\title{
Rupture Process of the February 4, 1965, Rat Islands Earthquake
}

\author{
SUSAN L. BeCK' \\ Earth Sciences Department and Institute of Geophysics and Planetary Physics \\ Lawrence Livermore National Laboratory, Livermore, California
}

\section{Douglas H. Christensen}

Geophysical Institute, University of Alaska, Fairbanks

\begin{abstract}
The great Rat Islands underthrusting earthquake $\left(M_{w}=8.7\right)$, of February 4, 1965, represents subduction of the Pacific plate beneath the North American plate along a $600-\mathrm{km}$ segment of the western end of the Aleutian Islands. Body wave inversion techniques are used to determine the spatial and temporal heterogeneities associated with the Rat Islands earthquake. We have deconvolved World-Wide Standard Seismograph Network long-period teleseismic $\boldsymbol{P}$ wave seismograms to obtain source time functions. Directivity associated with the three major pulses of moment release in the source time functions indicates a total source duration of $160 \mathrm{~s}$, unilateral rupture in the direction $300^{\circ}$, fault length of $420 \mathrm{~km}$, and average rupture velocity of $2.5 \mathrm{~km} / \mathrm{s}$. The three pulses of moment release are located along the fault, and these regions of high moment release are interpreted as asperities. The first asperity extends from the epicenter to $100 \mathrm{~km}$ to the WNW. This is the largest asperity and corresponds to a smooth pulse of moment release in the source time function with a duration of $50 \mathrm{~s}$. The second pulse of moment release is very jagged, is less coherent between stations, and is centered $\sim 200 \mathrm{~km}$ WNW of the epicenter. The third pulse of moment release extends from 360 to $420 \mathrm{~km} \mathrm{WNW}$ of the epicenter. Although the aftershock area is $\sim 600 \mathrm{~km}$ in length, we can not resolve any moment release from the $P$ waves beyond $\sim 420 \mathrm{~km}$ WNW of the epicenter. The Rat Islands event was closely followed by a large tensional outer-rise event on March 30,1965, $\left(M_{s}=7.5\right)$, which is located oceanward of the largest moment release associated with the Rat Islands mainshock rupture. Detailed analysis of the $\boldsymbol{P}$ waves for this large outer-rise event confine the depth extent to the upper 30-35 km of the crust. The spatial and temporal association between the February 4 mainshock and the March 30 tensional outer-rise event suggests the tensional event may have been triggered by the large displacement near the mainshock epicenter. The overriding plate along the western Aleutian subduction zone is laterally segmented into a series of rigid tectonic blocks separated by fault controlled canyons and extensional basins (Geist et al., 1988). We suggest that the central undeformed parts of the blocks have the strongest coupling with the down-going plate and hence are the sites of the largest moment release during an underthrusting earthquake. The three asperities determined from the $\boldsymbol{P}$ waves correspond to the Rat, Buldir, and Near tectonic blocks respectively. Hence the $\boldsymbol{P}$ wave seismic moment release of the Rat Islands earthquake is controlled by the lateral segmentation of the overriding plate.
\end{abstract}

\section{INTRODUCTION}

Many of the variations associated with the occurrence of earthquakes can be explained by spatial heterogeneity in the mechanical properties of the fault plane [Kanamori, 1981]. In this model a fault consists of patches having different failure strengths. The heterogeneity in failure strengths along a fault segment will not only control the rupture of the largest earthquakes but also control the observed seismicity patterns. Recently many studies have identified temporal and spatial heterogeneity associated with the rupture of an individual earthquake [e.g., Beck and Ruff, 1984; Schwartz and Ruff, 1987; Boyd and Nabelek, 1988; Choy and Dewey, 1988; Houston and Engdal, 1989].

The asperity model is a simple fault heterogeneity model which provides a good framework in which to interpret the complex occurrence of earthquakes [Lay et al., 1982]. The fault consists of "strong" and "weak" regions. The stron-

\footnotetext{
${ }^{1}$ Now at Department of Geosciences, University of Arizona, Tucson.
}

Copyright 1991 by the American Geophysical Union.

Paper number 90JB02092.

0148-0227/91/90JB-02092\$05.00 gest regions are often termed asperities and have a higher failure stress than the weaker regions. The essential feature of the asperity model is that the largest earthquake occurs when the dominant asperity breaks. The weaker regions slip at a lower level of applied stress and may slip seismically with the large earthquakes but with smaller displacements or they may slip aseismically. A primary feature of the asperity model is that the coseismic displacement during an earthquake is largest at the asperity. For large earthquakes, teleseimic $\boldsymbol{P}$ waves can be used to determine the temporal and spatial heterogeneity in seismic moment release associated with the earthquake rupture. Regions of relatively high moment release are interpreted as asperities. However, the physical properties of these seismically determined asperities are not well understood. Efforts to identify bathymetric features on the downgoing plate that correlate with the asperities have generally been unsuccessful. In addition, we do not understand the interaction of adjacent asperities along a plate boundary segment or the variations between successive earthquake cycles. The February 4, 1965, Rat Islands earthquake $\left(M_{w}=8.7\right)$ yields information about not only the details of the rupture of a truly great earthquake but also some insight into asperity interaction and correlation with the lateral segmentation along the plate boundary. 


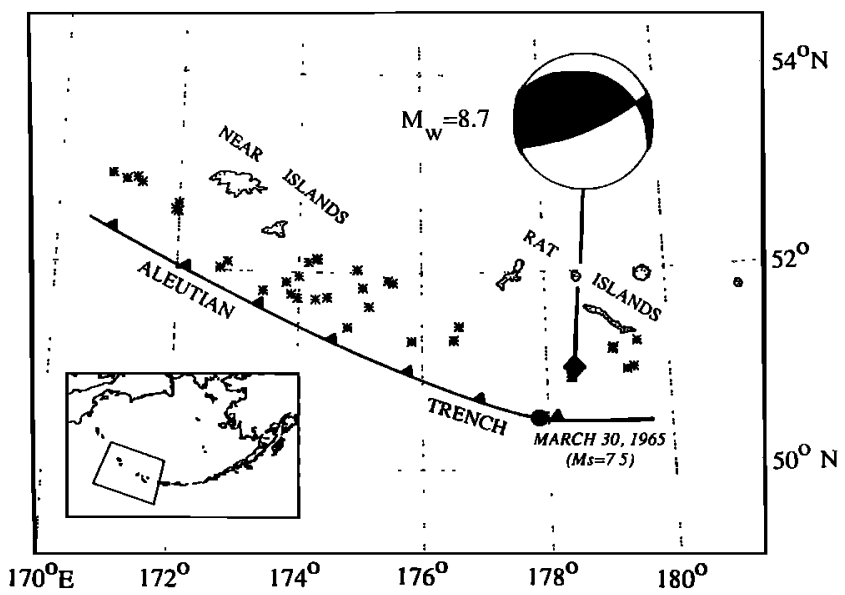

Fig. 1. Map of the western Aleutian arc showing the epicenter (large solid diamond) of the February 4, 1965, Rat Islands mainshock. The small stars are the aftershocks with $M>5$ relocated by Spence [1977], that occurred between February 4 and March 30, 1965. The focal mechanism for the mainshock is from the surface wave study of $W u$ and Kanamori [1973].

The 1965 Rat Islands earthquake is one of the largest underthrusting earthquakes to occur since the deployment of the World-Wide Standard Seismograph Network (WWSSN). This earthquake represents subduction of the Pacific plate beneath the North American plate along a $600-\mathrm{km}$ segment of the western end of the Aleutian Islands (Figure 1). We have studied the temporal and spatial heterogeneities associated with the rupture of the 1965 Rat Islands earthquake. The large seismic moment determined from surface waves $\left(140 \times 10^{27}\right.$ dyn $\mathrm{cm}$ [Wu and Kanamori, 1973]) and the long aftershock area $(\sim 600 \mathrm{~km}$ along strike) allow us to study the fault plane heterogeneities associated with a great subduction zone earthquake. We have compared the spatial heterogeneities of the mainshock with the aftershocks and the lateral segmentation along the subduction zone. There is a good correlation between the spatial moment release as determined from the $P$ waves for the mainshock and the lateral segmentation of the overriding plate.

This segment of the plate boundary had a sequence of several smaller earthquakes between 1898 and 1929. It is not clear if this sequence of earthquakes at the turn of the century represents the previous earthquake cycle and is equivalent to the 1965 Rat Islands earthquake.

\section{The February 4, 1965, Rat IsLands MaINSHOCK}

\section{Data and Methods}

For an earthquake this large, most of the WWSSN nondiffracted long-period vertical $\boldsymbol{P}$ waves are off scale. Hence very few studies have been done on the body waves of such large earthquakes. We have used both long-period nondiffracted horizontal and diffracted vertical $P$ wave seismograms. Amplitudes of horizontal components were corrected to the equivalent vertical amplitudes for analysis by applying horizontal receiver factors which were determined by comparing horizontal and vertical component amplitudes for the first few $P$ wave cycles or by using a theoretical correction [Bullen, 1963] if the vertical component went off-scale immediately. We have also used diffracted $\boldsymbol{P}$ waves in order to increase the azimuthal coverage and determine the total source duration. For such a large earthquake the source duration is longer than the time window between $\boldsymbol{P}$ and $\boldsymbol{P P}$ phases for seismograms recorded at distances less than $\sim 70^{\circ}$. Therefore the diffracted $P$ waves are important for determining the total source duration.

We have used several techniques to determine the temporal and spatial heterogeneities associated with faulting. Single-station source time functions are obtained using the deconvolution method of Ruff and Kanamori [1983]. We have used a water layer over a half-space to calculate the Green's functions. The Green's functions include the direct $P, p P$, and $s P$ surface reflections and ocean layer multiple reflections. Observable directivity, associated with consistent features in the source time functions, are used to determine the spatial location of the moment release on the fault plane. In addition, the single-station source time functions are inverted using a tomographic inversion method of Ruff [1987] that results in a space-time model of the earthquake rupture. This method searches for coherent features in the source time functions using a priori rupture azimuth and velocity. A large number of rupture azimuths and velocities can be tested easily and quickly, and a comparison of statistical parameters in the data and model space gives an indication of the best choice of parameters [Ruff, 1987]. We have also used a multistation iterative deconvolution method based on the technique of Kikuchi and Fukao [1985] to determine the temporal and spatial heterogeneities associated with faulting. This method does not require the same assumption of a constant rupture velocity. We have used several techniques in order to obtain the most reliable "view" of the rupture process for the 1965 Rat Islands earthquake.

\section{$P$ Wave Analysis}

The long-period $P$ waves for the February 4, 1965, earthquake are complex with a long duration and an emergent start (Figures $2 a$ and $2 b$ ). The start times for the $P$ waves were picked from short-period vertical components when possible. Single-station source time functions are deconvolved assuming a Green's function distributed over a depth range of $10-40 \mathrm{~km}$ (Figures $2 a$ and $2 b$ ). We tested for differences in the depth of faulting but could not resolve the depth between the surface and $50 \mathrm{~km}$ using the single-station inversion. The amount of time used in the deconvolution varies from station to station based on how much record we were able to digitize and the time window between the $P$ and $\boldsymbol{P P}$ arrivals. We were able to digitize from 1 to $4 \mathrm{~min}$ of 24 seismograms with 13 seismograms having $3 \mathrm{~min}$ or more. Figure $2 a$ shows source time functions for stations with a $P$ wave duration of at least $3 \mathrm{~min}$, while Figure $2 b$ shows source time functions for stations with a $P$ wave duration of less than $3 \mathrm{~min}$. The resultant source time functions are complex but consistently show at least three main pulses of seismic moment release with variable character and different durations.

The first pulse of moment release has a duration of 50-55 $s$ with a long ramp at the beginning. This initial ramp rises fairly smoothly for $\sim 40 \mathrm{~s}$. This pulse of moment release is fairly smooth. There is observable directivity associated with the truncation of the pulse. The initial truncation of the first pulse is labeled A1 in Figures $2 a$ and $2 b$. A second notch 

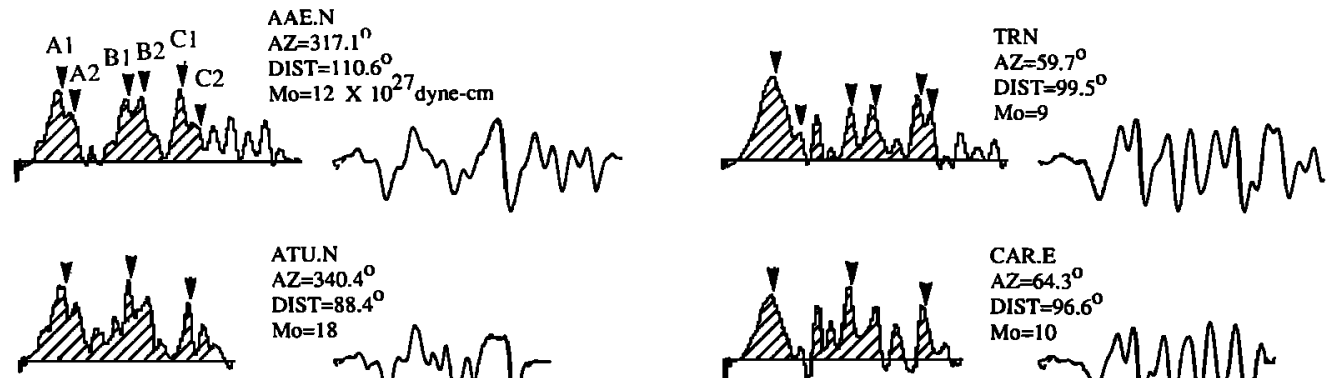

\section{ATU.N}

AIST $=88.4$

$\mathrm{DIST}=88$
$\mathrm{Mo}=18$
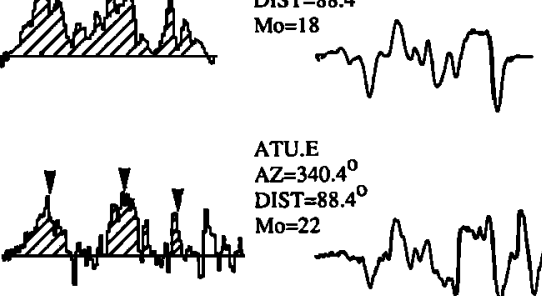

ATU.E

$\mathrm{AZ}=340.4^{\mathrm{O}}$

DIST $=88.4^{\circ}$

$\mathrm{Mo}=22$
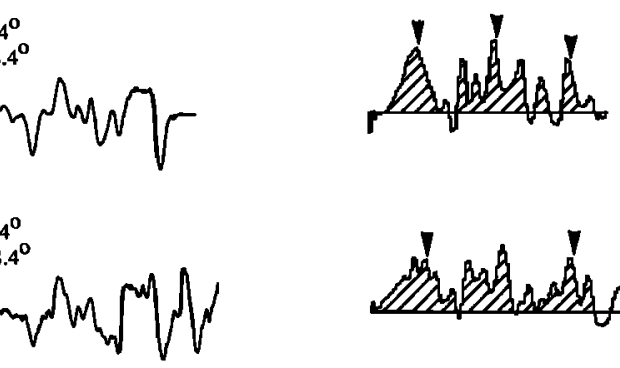

CARE

$\mathrm{AZ}=64.3^{\circ}{ }^{\circ}$

DIST $=96$.

$\stackrel{M}{M=10} N \| N$

LPB

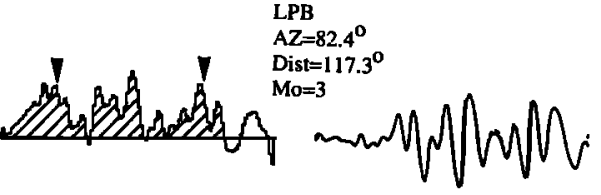

Estastan

COP.N

$\mathrm{AZ}=351.8^{\circ}$

DIST
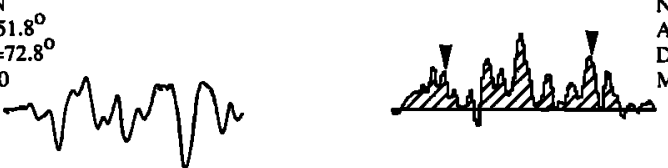

NNA

$\mathrm{AZ}=86.3$
$\mathrm{DIST}=108.4^{\circ}$

$M 0=8$
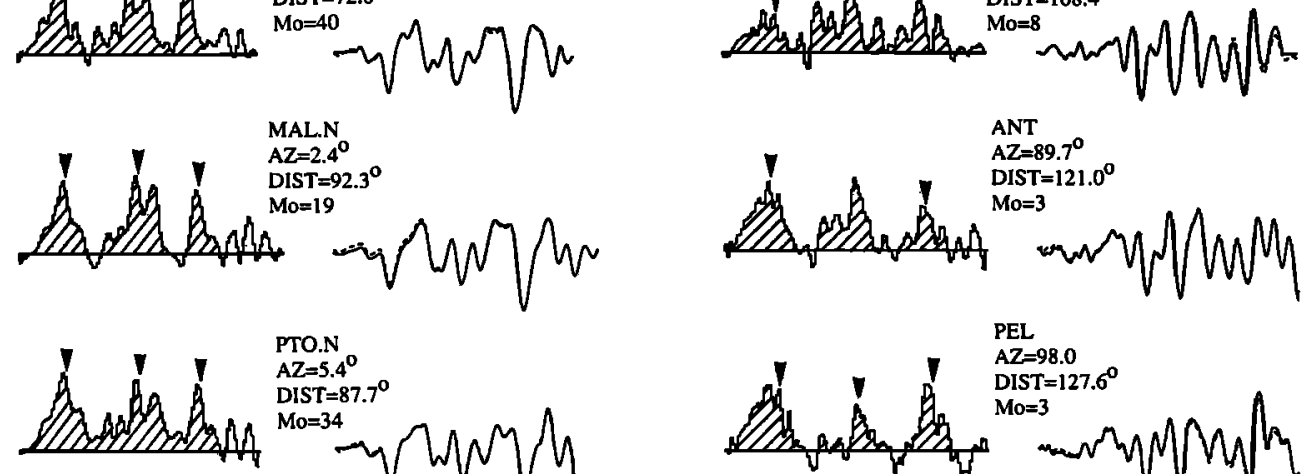

AZ $=5.4^{\circ}$

DIST $=87.7^{\circ}$

- $M$ N M M

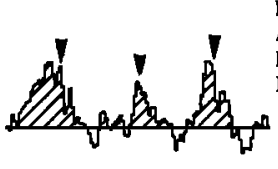

PEL

$\mathrm{AZ}=98.0$

DIST $=127.6^{\circ}$

$0=3$

m MNMNh

TAU

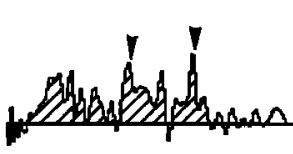

$\mathrm{Z}=202.6^{\circ}$

AZ $=202.6^{\circ}$

$\mathrm{Mo}=18$

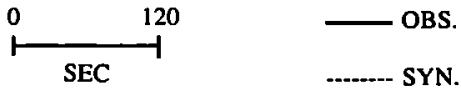

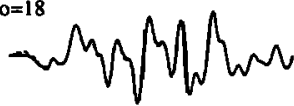

Fig. 2a. Deconvolved single-station source time functions for the February 4, 1965, Rat Islands earthquake. The solid trace is the observed seismogram, and the dashed trace is the synthetic seismogram for the source time function shown for each station. The station azimuth (AZ), epicentral distance (DIST), horizontal component (N, E) if used, and seismic moment $\left(M_{0}\right)$ are shown for each station. The source time functions show three main pulses of moment release (A, B, C). Within each pulse of moment release the consistent features that can be observed at many stations are shown by the arrows (A1, B1, C1). The first source time function has additional arrows showing the secondary features (A2, $B 2, C 2)$ that are less consistent from station to station.

on the downgoing side of the first pulse (labeled A2) is also observed on the source time functions recorded on nondiffracted stations. The second pulse of moment release is less coherent from station to station and consist of two to three subpulses. Stations to the NW and north show two subpulses. Stations to the NE and east show a more complex series of three subpulses. It is hard to pick consistent features associated with this pulse of moment release for directivity analysis. The third pulse of moment release has a duration of 25-30 s and is consistent from station to station. The truncation (labeled $\mathrm{Cl}$ in Figures $2 a$ and $2 b$ ) of the third pulse of moment release shows consistent directivity. For example, the third pulse of moment release is truncated at $142 \mathrm{~s}$ at stations to the NW and $172 \mathrm{~s}$ at stations to the ENE indicating a maximum directivity of $30 \mathrm{~s}$. The observable directivity allows us to locate spatially the temporal moment release along the fault for the consistent features in the source time functions.

The directivity analysis consists of identifying consistent features in the source time functions from different stations and using the variation in timing relative to the initial onset of the $\boldsymbol{P}$ wave to spatially locate the feature (for a more detailed discussion see Beck and Ruff [1984]). The observed delay time of any feature at the $i$ th station relative to the epicentral arrival time $T_{i}$ is linearly related to $X$ and $t$ by $T_{i}=\Gamma_{i} X+t$, where $\Gamma$ is the directivity parameter for the $i$ th station (product of the ray parameter and the cosine of the angle between the rupture azimuth and station azimuth). The distance $X$ and the actual delay time $t$ of the feature are given by the slope and $y$ intercept, respectively, of the best fit line through the data (Figure 3). In order to determine the best rupture direction we step through all possible rupture azi- 


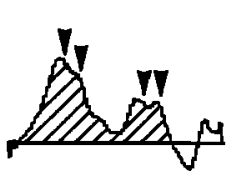

BUL

$\mathrm{AZ}=311.7^{\circ}$

DIST $=141.0^{\circ}$

$\mathrm{Mo}=2$

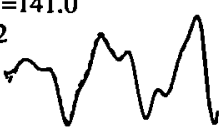

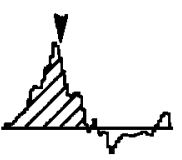

VAL.N

$\mathrm{AZ}=5.6$

DIST $=76.9$

$\mathrm{Mo}=15$
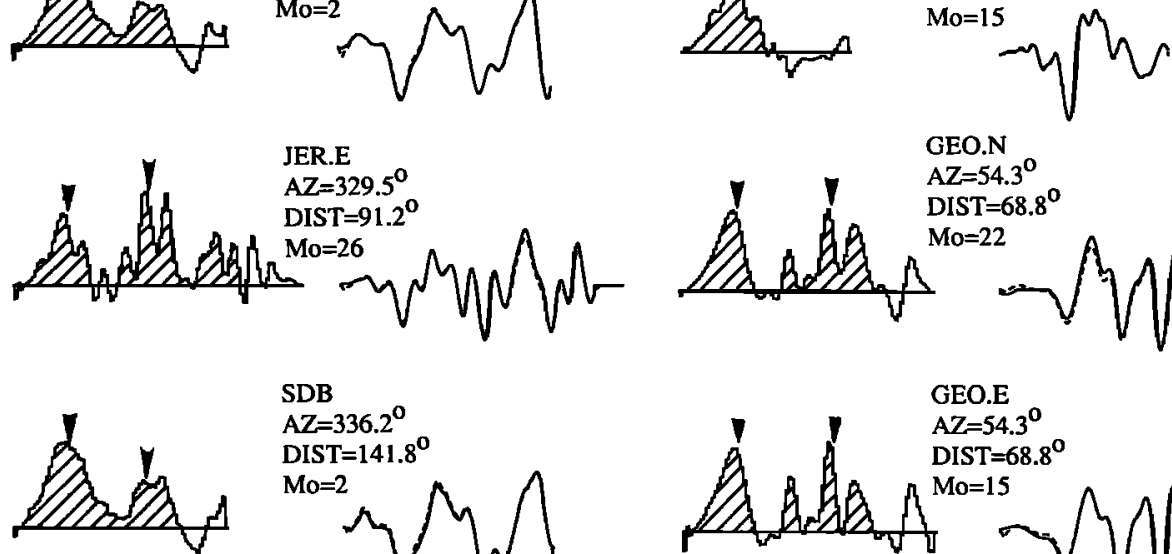

JER.E

$\mathrm{AZ}=329.5^{\circ}$

DIST $=91.2^{\circ}$ $\mathrm{Mo}=26$
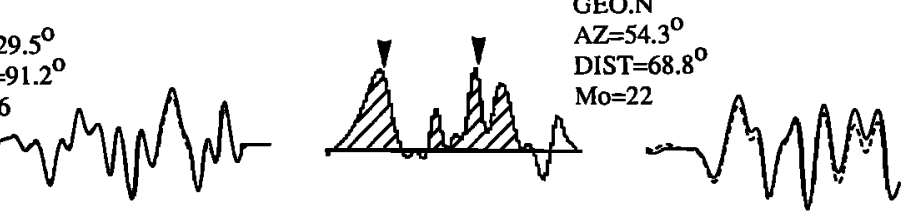

SDB

$\mathrm{AZ}=336.2^{\circ}$

DIST $=141.8^{\circ}$

$\mathrm{Mo}=2$
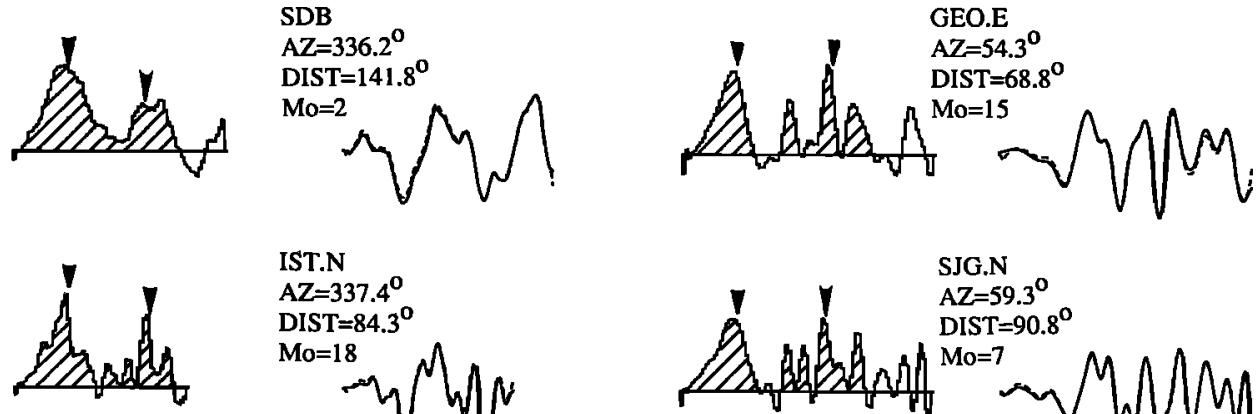

IST.N

$\mathrm{AZ}=337.4^{\circ}$

DIST $=84.3^{\circ}$

$\mathrm{Mo}=18$
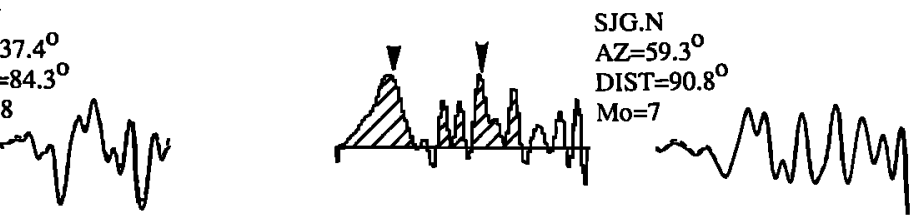

STU.N

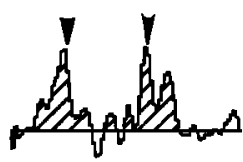

AZ $=352.9^{\circ}$

DIST $=79.9^{\circ}$

$\mathrm{Mo}=16$
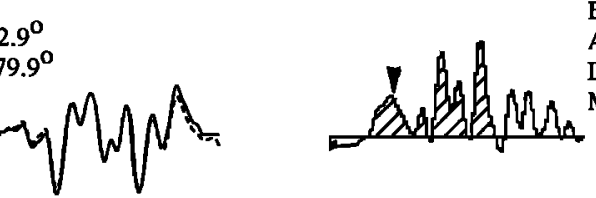

BHP.N

$\mathrm{AZ}=75.2^{\circ}$

DIST $=90.4^{\circ}$

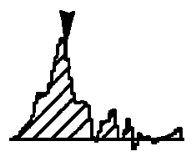

ESK.N

$\mathrm{AZ}=1.0^{\circ}$

DIST $=73.7^{\circ}$

$\mathrm{Mo}=16$
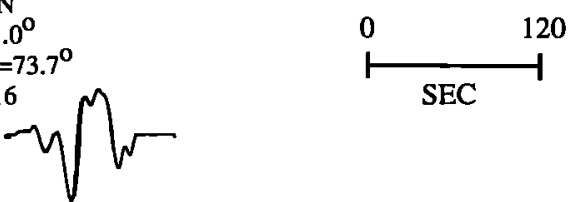

OBS.

SYN.

Fig. $2 b$. The same as Figure $2 a$ except that the $P$ waves for these stations have a duration of 3 min or less.

muths and find the azimuth that produces the overall best fit straight line (Figure 3).

Although the first pulse of moment release is smooth, we were able to pick the time at which the pulse begins to go down (labeled A1) for 21 stations and a consistent notch on the decreasing side of the pulse (labeled A2) for 12 stations that were not diffracted. The truncation of the first pulse (A1) occurs at $41.4 \pm 0.3 \mathrm{~s}$ and is located $103 \pm 11 \mathrm{~km} \mathrm{WNW}$ of the epicenter (Figure 3). This gives an apparent rupture velocity of $2.49 \mathrm{~km} / \mathrm{s}$. The secondary notch (A2) occurs at $51.0 \pm 0.5 \mathrm{~s}$ and is located at $107 \pm 17 \mathrm{~km} \mathrm{WNW}$ of the epicenter essentially the same location as A1. Both these locations give correlation coefficients of 0.90 and 0.79 , respectively, for the best fit straight line for a rupture direction of $300^{\circ}$ (Figure 3 ).

The second pulse of moment release is variable in character, making it harder to correlate coherent features between stations. It is hard to know how the two subpulses at one station compare to the three subpulses at another station. We looked at the directivity associated with the largest subpulse (B1) at 15 stations and found a delay time of $100.8 \pm 0.5 \mathrm{~s}$ and a location $223 \pm 18 \mathrm{~km} \mathrm{WNW}$ of the epicenter. However, this location is not very reliable due to the variable character of the pulse. In order to determine the coherency of this second pulse of moment release, we have used two other inversion techniques discussed in the next two sections.

The third pulse is a sharp feature on the source time functions. Directivity analysis indicates a time delay of $156.5 \pm 0.2 \mathrm{~s}$ and a location $386 \pm 18 \mathrm{~km} \mathrm{WNW}$ of the epicenter for the truncation of the third pulse (labeled $\mathrm{C} 1$ in Figure $2 a$ ). This gives an overall average rupture velocity of $2.47 \mathrm{~km} / \mathrm{s}$. The secondary notch $\mathrm{C} 2$ yields a location of $385 \pm$ $17 \mathrm{~km}$ and a delay time of $168.3 \pm 0.5 \mathrm{~s}$. The correlation coefficient for the best fit straight line is 0.99 for a rupture direction of $290^{\circ}$ to $300^{\circ}$ for both C1 and C2 (Figure 3). After the third pulse of moment release we see no coherent moment release in the source time functions. However, there could be low level moment release that is not resolvable in the body waves.

It is hard to determine the seismic moment from $P$ waves for this earthquake because we do not have any vertical nondiffracted $P$ waves. Stations such as COP $\left(72.8^{\circ}\right)$ and PTO $\left(87.7^{\circ}\right)$ give seismic moments of 42 and $34 \times 10^{27}$ dyn 
$\mathrm{cm}$, respectively. This is much less than the surface wave moment of $140 \times 10^{27} \mathrm{dyn} \mathrm{cm}$ [Wu and Kanamori, 1973]. Seismic moment determinations of great earthquakes from body waves tend to underestimate the total seismic moment release due to the limited passband of the instrument. However, the body waves are more sensitive to the rupture complexities than surface waves. As discussed by Beck and Ruff [1985] for large earthquakes, the true static seismic moment or zero frequency value of the Fourier transform of the moment rate function is not recorded and must be estimated. If the corner frequency is recorded in the passband of the data, then the flat part of the spectrum can be extrapolated back to zero frequency. However, if the corner frequency is outside the passband of the data, then the extrapolation to the zero frequency will underestimate the true total static seismic moment. In time domain the seismic moment is equivalent to the positive area under the source time function. The discrepancy in moment release between the $\boldsymbol{P}$ waves and the surface waves indicates that a longperiod component of moment release is not accounted for in our $P$ wave modeling. In order to investigate the general nature of this missing moment, we have added in the long-period seismic moment release so the total moment is $140 \times 10^{27}$ dyn cm for station COP in two different ways (Figure 4). First, we constrain the moment release to be confined to the three pulses of moment release; this model fails to match the observed data (Figure 4). Second, the additional moment release is added in as a long-period half sine wave over $240 \mathrm{~s}$. This corresponds to a fault length of $600 \mathrm{~km}$. Notice that the synthetic seismogram fits the observed seismogram extremely well (Figure 4). Although this result is not unique, it does indicate that the additional moment is released in a smooth fashion over a large area. This implies that there is substantial longer-period moment released in the areas between the asperities.

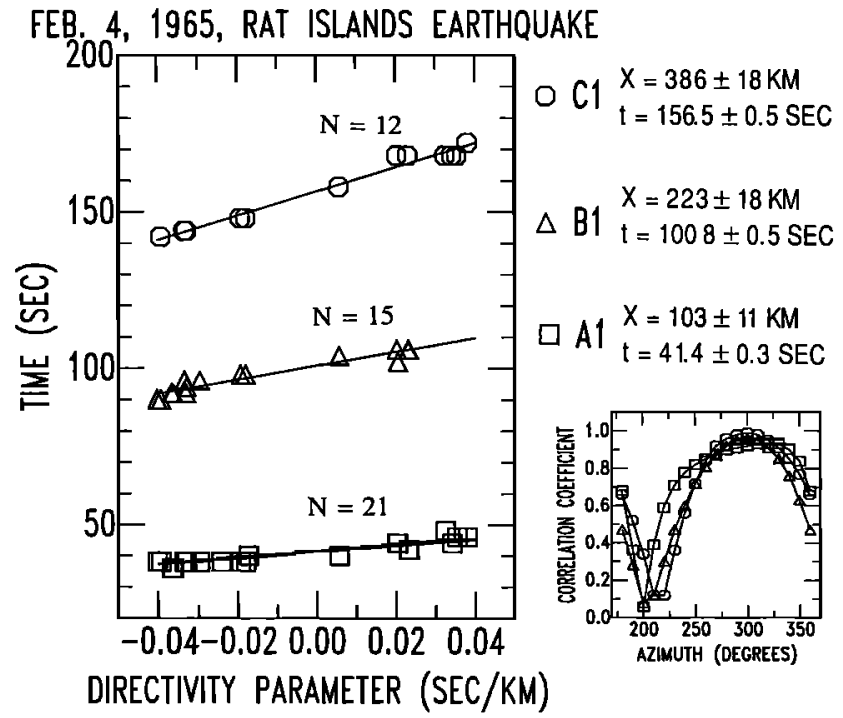

Fig. 3. Best fit (least squares) straight lines for the delay time $T_{i}$ versus directivity parameter $(p \cos \phi)_{i}$ for each station for the three main features identified on the source time functions (A1, B1, C1). The slope of the line $(X)$ gives the horizontal distance to the feature and the zero intercept $(t)$ gives the actual delay time. The best rupture direction is $300^{\circ}$ for each feature. The plot in the lower right shows the correlation coefficients of the best fit straight lines as a function of the assumed rupture azimuth for each feature.
$\operatorname{COP} A Z=352^{\circ} D I S T=73^{\circ}$

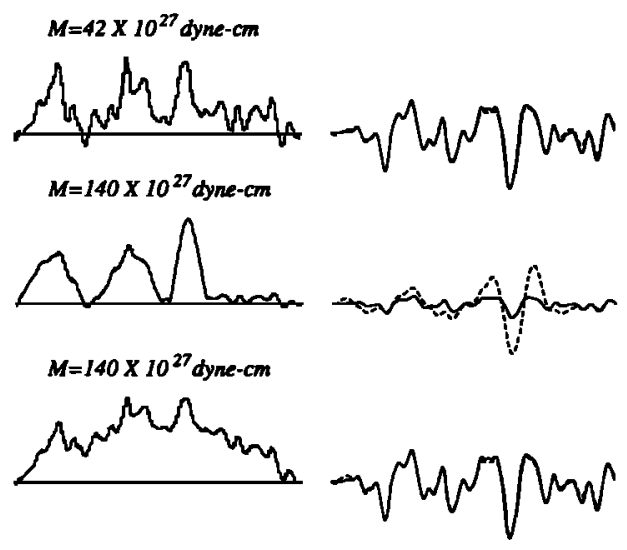

Fig. 4. The top row is the single station inversion of the $P$ wave for station COP which yields a seismic moment of $42 \times 10^{27} \mathrm{dyn} \mathrm{cm}$. In the second row, the surface wave seismic moment of $140 \times 10^{27}$ dyn $\mathrm{cm}$ is constrained to the three pulses of moment release in the source time function. The synthetic seismogram does not fit the observed data indicating the missing moment cannot be confined to the asperities. The bottom row shows the total seismic moment added in as a half sine wave with a duration of $240 \mathrm{sec}$ to correspond to a fault length of $600 \mathrm{~km}$. In this case the synthetic seismogram fits the data very well. Although this result is not unique, it indicates that the additional moment is released in a smooth fashion distributed over a large area.

\section{Tomographic Inversion}

To determine quantitatively the moment release along the fault, we have used the inversion method devised by $R$ uff [1987]. This method makes several assumptions about the earthquake rupture. First, the fault length is much longer than the width; therefore we solve only for one spatial dimension. In this case the fault length is $\sim 600 \mathrm{~km}$ and the width is $\sim 50-70 \mathrm{~km}$. Second, this method also assumes that the rupture front spreads out from the epicenter and that most of the displacement or moment release occurs as the rupture front passes by. In other words, a portion of the fault does not rerupture after the rupture front has gone by. If we accept this view of earthquake rupture, then we can invert for coherent features along the one dimension of the fault.

We have inverted the previously determined single station source time functions for a space-time image of the rupture [Ruff, 1987]. The single-station source time functions are the back projection or more formally the radon transform of the moment rate density function. This method uses a priori estimates of the rupture azimuth and velocity and iteratively determines the moment release distribution that best fits the observed time functions in a least squares sense. A large number of rupture azimuths and velocities can be tested easily and quickly, and the best overall fit to the time functions gives the best choice of rupture parameters.

We first tested a fault with a unilateral rupture from 0 to $600 \mathrm{~km}$, discretized with a 20-km spatial interval and 240-s source time function duration. We used 12 stations where the source time functions had a duration of $240 \mathrm{~s}$. The source time functions were baseline normalized to have zero moment in order to determine the best rupture azimuth. Synthetic source time functions were produced for each model image. The match between the synthetic and observed source function is measured by the parameter $e$, the ratio of 

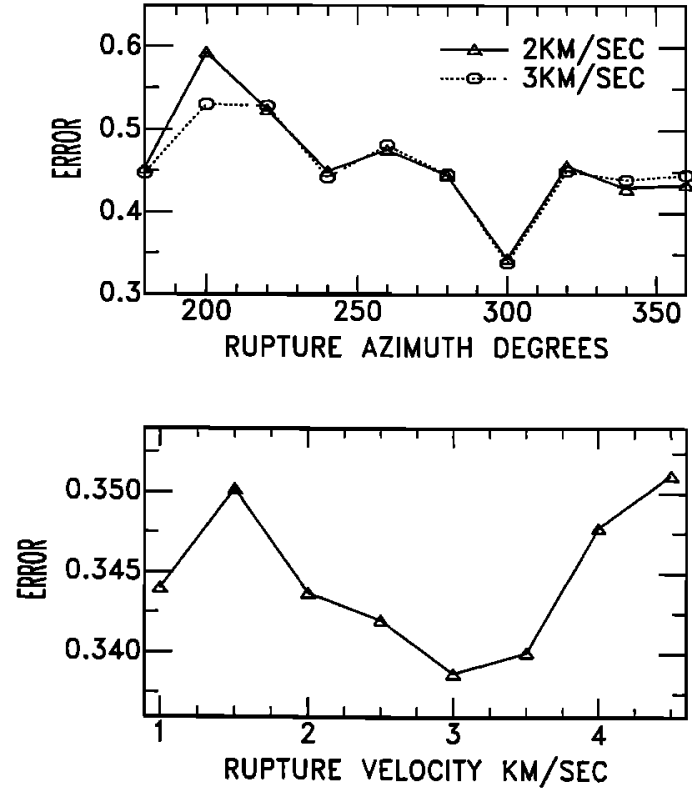

Fig. 5. Plots showing the tomographic imaging error versus rupture azimuth and rupture velocity. For all rupture velocities the lowest error corresponds to a rupture azimuth of $300^{\circ}$. The rupture velocity is not well resolved.

the error vector length to the data vector length. After 10 iterations there was very little decrease in the error parameter. In order to determine the best rupture azimuth, the inversion is performed systematically for a large range of azimuths. Figure 5 shows that $300^{\circ}$ yields the smallest value of $e$ for all rupture velocities. We also tested for rupture velocity but found very little resolution between 2.0 and 3.5 $\mathrm{km} / \mathrm{s}$. We tested for a bilateral rupture in order to determine if there was any resolvable moment release ESE of the epicenter. In this case, the initial model estimate has moment release symmetric about the epicenter but with each successive iteration the moment release is concentrated in the WNW direction. Hence the rupture appears to be unilateral to the WNW direction.

For our final model we use a rupture azimuth of $300^{\circ}$, a rupture velocity of $2.5 \mathrm{~km} / \mathrm{s}$ determined from the directivity analysis, and a fault length of $500 \mathrm{~km}$ (Figure 6). We also normalized the source time functions to have a seismic moment of $30 \times 10^{27} \mathrm{dyn} \mathrm{cm}$, the average seismic moment determined from the $P$ waves. Figure 6 shows the first and tenth iteration of the rupture image and data. The results of the inversion are similar to our previous results. There are three main pulses of moment release. We find no coherent moment release after $160 \mathrm{~s}$ which corresponds spatially to beyond $\sim 400 \mathrm{~km} \mathrm{WNW}$ of the epicenter. If we use a rupture velocity of $3.0 \mathrm{~km} / \mathrm{s}$, the third pulse of moment release occurs $\sim 460 \mathrm{~km} \mathrm{WNW}$ of the epicenter. This method computes the time integrated moment density along the fault shown in Figure 7, where the three regions of peak moment release are label $\mathrm{A}, \mathrm{B}$, and $\mathrm{C}$.

From the $P$ waves we can identify three regions of concentrated moment release. We interpret these as asperities for the 1965 Rat Island earthquake. The first asperity corresponds to a smooth rupture occurring between the epicenter and $100 \mathrm{~km}$ to the WNW. The second region of moment release is less coherent and probably a series of
RUPTURE IMAGE

$\mathrm{AZ}=300^{\circ} \quad \mathrm{Vr}=2.5 \mathrm{~km} / \mathrm{sec}$
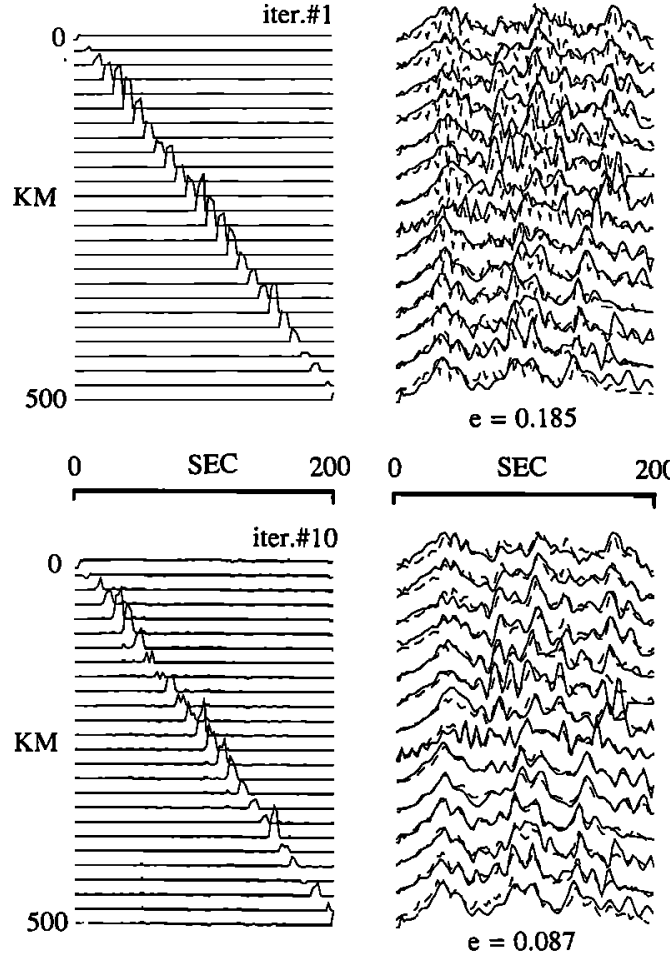

— OBS. -..-- SYN.

Fig. 6. Final space-time image of the rupture process of the February 4, 1965, Rat Islands earthquake from the tomographic imaging technique. The data on the right are the previously determined source time functions shown as the solid traces. The dashed traces are the synthetic source time functions for the rupture model shown on the left. The rupture image has spatial extent from 0 (corresponding to the epicenter) to $500 \mathrm{~km}$ in the direction of $300^{\circ}$ and an a priori rupture velocity of $2.5 \mathrm{~km} / \mathrm{s}$. The rupture image shows three pulses of moment release.

FEB. 4, 1965, RAT ISLANDS EARTHQUAKE

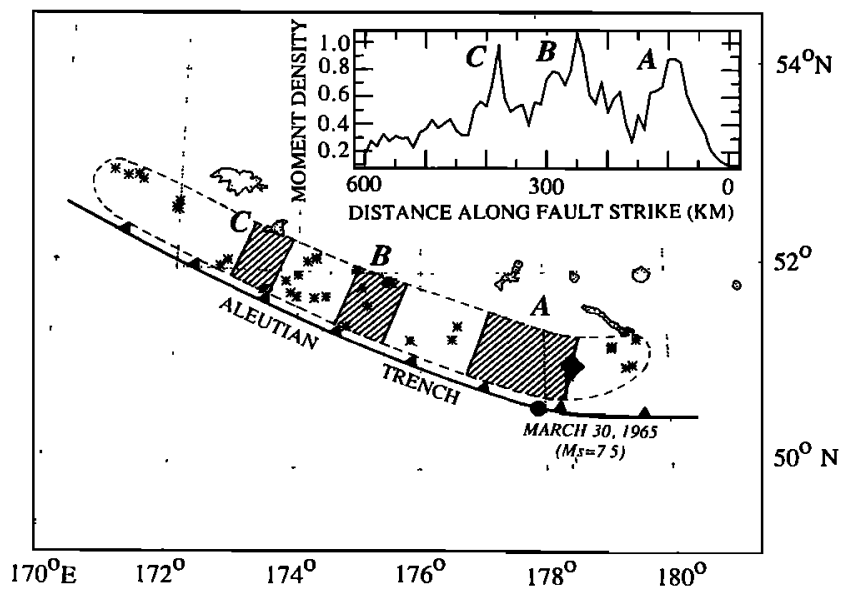

Fig. 7. Map view of the first-order asperity distribution for the February 4, 1965, Rat Islands earthquake. The insert shows the moment rate density function with units of $10^{-1} \mathrm{dyn} \mathrm{cm} / \mathrm{km}$ along the fault strike based on the tomographic imaging. The asperities are shown in map view. There is a lack of aftershocks occurring in the first and third asperity regions. 


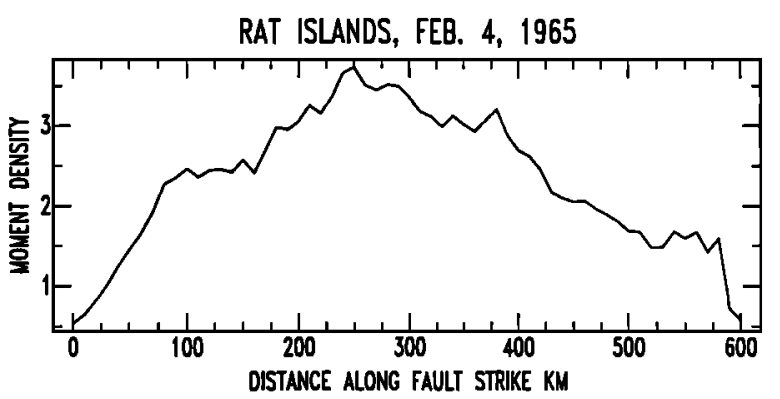

Fig. 8. Moment rate density function from the tomographic imaging constrained to have a total seismic moment of $140 \times 10^{27}$ dyn $\mathrm{cm}$. The additional moment release is added as a long-period half sine wave. The moment rate density is in units of $10^{-1}$ dyn $\mathrm{cm} / \mathbf{k m}$.

small asperities close together in time and space. The third asperity is coherent from station to station but much shorter in duration and spatial extent than the first asperity and occurs between 360 and $420 \mathrm{~km}$ WNW of the epicenter. Although the aftershocks extend for $\sim 600 \mathrm{~km}$ WNW of the epicenter, we cannot resolve any moment release after $\sim 400-460 \mathrm{~km} \mathrm{WNW}$ of the epicenter.

The moment release determined from the $P$ waves is less than one-third the surface wave moment. We have also used the tomographic inversion including the entire surface wave moment $\left(140 \times 10^{27} \mathrm{dyn} \mathrm{cm}\right)$. Of course, there is no spatial resolution on the additional moment which is added to the source time functions as a smooth half sine wave. The resultant moment rate density function is shown in Figure 8. We can estimate the resolvable peak seismic displacement from this moment density, assuming a fault width and a rigidity. For a fault width of $60 \mathrm{~km}$ and a rigidity of $5 \times 10^{11}$ $\mathrm{dyn} / \mathrm{cm}^{2}$, the resolvable peak seismic displacement is $\sim 12$ $\mathrm{m}$. The average seismic displacement for a uniform fault with dimensions $600 \mathrm{~km} \times 60 \mathrm{~km}$ is $7.5 \mathrm{~m}$. A larger fault width would of course decrease the displacement.

\section{Multistation Inversion}

We have also used an iterative, multiple-station deconvolution method for a finite source model developed by Kikuchi and Kanamori [1982] and more recently by Kikuchi and Fukao [1985]. This technique fits all the observed seismograms with a single source history. An unit wavelet is constructed assuming a fixed trapezoid rise time and duration, focal mechanism, and hypocentral depth. The wavelet is correlated with the observed seismograms to determine the best delay time, amplitude, and spatial location on the fault grid. The wavelet is then stripped out of the seismograms, and the procedure is repeated on the residual waveform. In this way an individual seismic moment pulse is located at a particular point on a spatial grid for each iteration. Unlike the constrained tomographic inversion discussed earlier, the iterative inversion does not require a priori estimates of rupture velocity, and the moment release is not compelled to lie on a propagating rupture front. However, a maximum rupture velocity is usually specified. These extra degrees of freedom, however, can cause the inversion to be unstable, and thus great care must be used interpreting the results. Although it is possible to invert for moment release on a fault surface (i.e., two dimensions), we

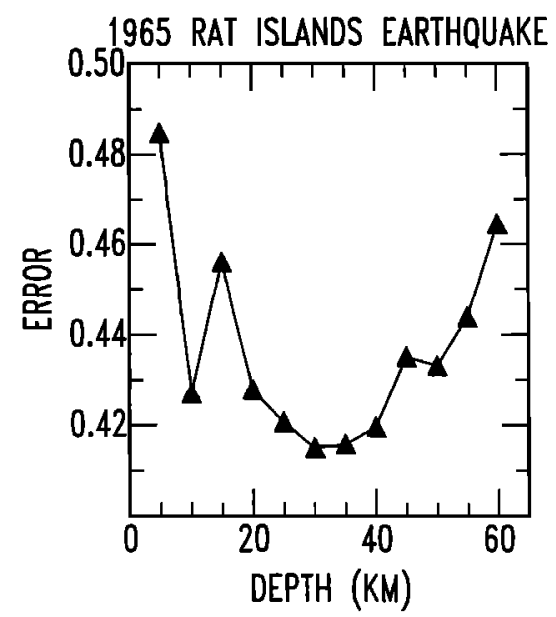

Fig. 9. Plot of the error for the multistation iterative inversion versus assumed depth. The very lowest error corresponds to a depth of $30 \mathrm{~km}$ with acceptable errors between 10 and $45 \mathrm{~km}$.

have limited our inversion to one dimension (i.e., ribbon fault), along the strike of the fault in order to help constrain the results. This constraint is reasonable for large underthrusting subduction zone earthquakes with the along-strike dimension much larger than the width.

We systematically tested for the best trapezoid shape and hypocentral depth to use in the inversion (Figure 9). For the final mode we used a trapezoid with a rise time of $4 \mathrm{~s}$ and a total duration of $14 \mathrm{~s}$ (i.e., $4-6-4 \mathrm{~s}$ ) and a depth of $30 \mathrm{~km}$. The surface wave focal mechanism was also assumed in the inversion. The fault grid starts at $120 \mathrm{~km}$ east of the epicenter and ends $600 \mathrm{~km}$ west of the epicenter, with a $60-\mathrm{km}$ grid spacing, thus encompassing the aftershock region. We inverted 240 s of the $P$ wave from 12 stations. Additional steps were employed as suggested by Young et al. [1989] to improve the weighting scheme used in calculating the fits to the seismograms. These include normalizing the observed waveforms to a common magnification and further normalizing the waveforms to a common power. This normalizing scheme forces all the waveforms, including nodal and diffracted $P$ waves, to have uniform weights in the inversion. Without this weighting the inversion would be dominated by the nondiffracted stations to the NNW and with the limited azimuth range we would have no spatial resolution. The synthetic wavelets were normalized in a similar way.

Our final rupture model from the multistation iterative inversion is very consistent with our previous results. Figure 10 shows the temporal and spatial locations of the individual subevents, and Figure 11 shows the fit between the observed and synthetic waveforms. It is important to interpret only the robust features of the inversion. The major pulses of moment release tend to fall on a line which indicates the moment release occurred along a rupture front with an apparent rupture velocity of about $2.5-3.0 \mathrm{~km} / \mathrm{s}$ (Figure 10 ). The three largest pulses are labeled $\mathrm{A}, \mathrm{B}, \mathrm{C}$ to correspond to previous figures. Moment release is concentrated near the epicenter and at the western end of the fault with a more dispersed region of moment release near the center of the rupture zone. Although 40 iterations were utilized to fit the waveforms, it is apparent from Figure 10 that the largest six subevents (largest triangles) account for most of the moment release. Young et al. [1989] have shown that the spatial 
FEB. 4, 1965 RAT ISLANDS EARTHQUAKE
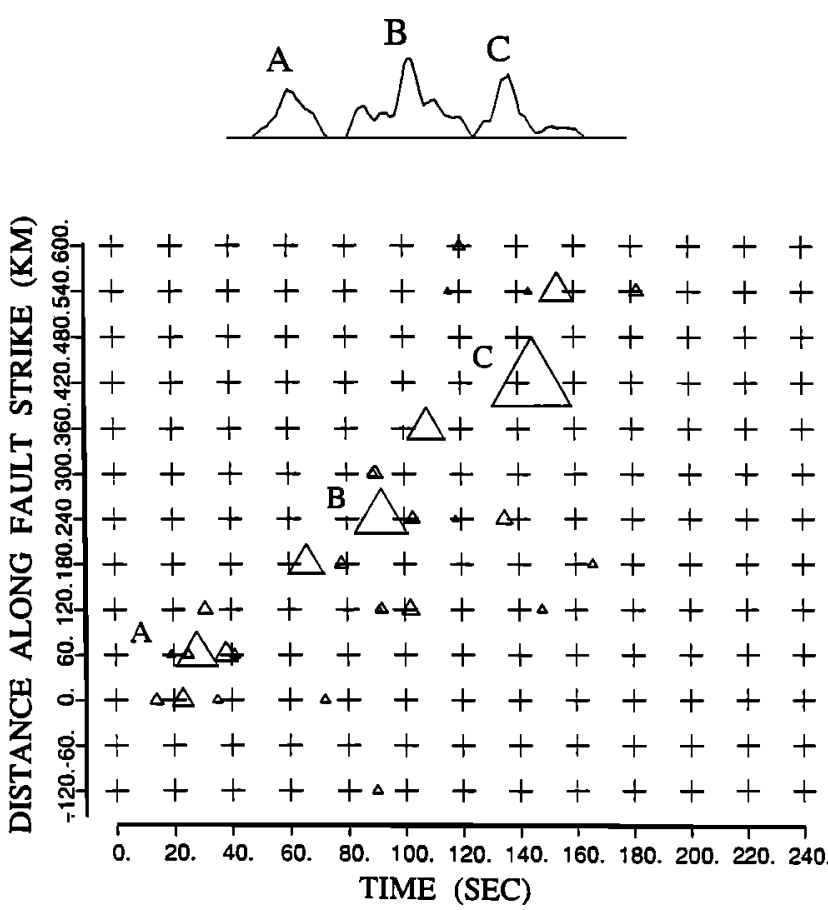

Fig. 10. Results of the multistation iterative inversion. The resultant source time function has three pulses of moment release similar to the single station source time functions. The lower diagram is a space-time plot of the moment release. The epicenter is at $0 \mathrm{~km}$ and the spatial dimension extends from $-120 \mathrm{~km}$ (ESE of the epicenter) to $+600 \mathrm{~km}$ (WNW of the epicenter). The temporal extent is from 0 to $240 \mathrm{~s}$. The triangles represent the best time and spatial location of the subevents for each iteration. The size of the triangles is proportional to the seismic moment release in each iteration. The largest subevents locate on a line indicating a fairly constant rupture velocity.

resolution of the Kikuchi and Kanamori [1982] technique is not reflected in the overall fit to the seismograms but needs to be evaluated separately for each subevent by looking at the correlation between the observed waveforms and the synthetic wavelet at the various allowable fault and time locations. Figure 12 shows a contour plot of the correlation coefficient function on the temporal and spatial grid for the largest subevent $(C)$. In Figure 12 the vertical axis is the distance along the fault from the epicenter and the horizontal axis is the time after the first arrival. The jagged leading edge of the plot is due to a maximum rupture velocity constraint, in this case $5 \mathrm{~km} / \mathrm{s}$. The white cross indicates the maximum value of the correlation coefficient and hence the location of the subevent. A peak of high values (dark shading) indicates good spatial resolution whereas a ridge of high values indicates poor resolution. There is usually good resolution in time but worse resolution in space. In Figure 12 the subevent (C) is located at $420 \mathrm{~km}$, but there are also fairly high correlations at the two adjacent grid points located at 360 and $480 \mathrm{~km}$. The larger the subevent the better the resolution so the earlier iterations have better resolution than the later iterations.

There is good agreement between the results using this multi-station iterative inversion and the tomographic inversion. The robust features of the earthquake rupture are strong unilateral rupture to the WNW with three main pulses of seismic moment release distributed along a strike of $\sim 300^{\circ}$ with an apparent rupture velocity between 2.5 and $3.0 \mathrm{~km} / \mathrm{s}$. With WWSSN long-period data we are unable to resolve the rupture velocity.

\section{Comparison With Other Studies}

$W u$ and Kanamori [1973] analyzed the radiation patterns and the amplitudes of the great circle Rayleigh and Love waves $\left(R_{5}\right.$ and $\left.G_{5}\right)$ in order to determine the seismic moment and faulting parameters for the Rat Islands earthquake. They found the following: fault plane dip $18^{\circ}$, dip direction $N 19^{\circ} \mathrm{E}$, rupture propagation direction $\mathrm{N} 51^{\circ} \mathrm{W}$, fault length $500 \mathrm{~km}$, rupture velocity $4.0 \mathrm{~km} / \mathrm{s}$, and seismic moment $140 \times 10^{27}$ dyn $\mathrm{cm}$. More recently, H. Kanamori (personal communication, 1989) has checked this previously determined seismic moment value based on the surface waves and found it to be correct. These are average parameters based on 100- to 500-s waves. The $P$ waves in the period range of $10-40 \mathrm{~s}$ contain more details of the rupture process. The $P$ wave study also gives a similar rupture direction $\sim 300^{\circ}$ but a slower average rupture velocity of $2.5-3.0 \mathrm{~km} / \mathrm{s}$. However, neither study has good resolution of the rupture velocity. We can resolve a source duration of $168 \mathrm{~s}$ and a corresponding fault length of $\sim 420 \mathrm{~km}$. However, there could be low level moment release out to $600 \mathrm{~km}$ where the aftershock area ends. In this case, we might expect the surface waves to give an average such as $500 \mathrm{~km}$. Our body wave study agrees reasonably well with the surface wave study of $W u$ and Kanamori [1973].

$W u$ and Kanamori [1973] also analyzed the first $35 \mathrm{~s}$ of the long-period $P$ waves to identify subevents. They found three subevents in the first $35 \mathrm{~s}$, and all the subevents were located south of the epicenter near the trench with delay times relative to the epicenter of $6.5,14.7$, and $20.8 \mathrm{~s}$, respectively. Directivity analysis indicates locations south of the epicenter of 33,86 , and $140 \mathrm{~km}$ and large apparent rupture velocities of $5-7 \mathrm{~km} / \mathrm{s}$. In contrast, Mori [1984] analyzed the first $35 \mathrm{~s}$ of the long-period records and found a rupture direction WNW for these subevents. Mori [1984] found locations of 90 and 89 $\mathrm{km}$, delay times of 12 and $22 \mathrm{~s}$, and azimuths of $285^{\circ}$ and $280^{\circ}$, respectively, for the two subevents from the longperiod $P$ waves. These values indicate very high rupture velocities of 7.5 and $4.0 \mathrm{~km} / \mathrm{s}$. The main difference in the two studies is that Mori [1984] used earlier arrival times at stations to the south, thereby delaying the time to the subevents. Mori [1984] used arrival times predicted by the International Seismological Centre (ISC) location. In addition, Mori restricted his analysis to azimuths which had the same wave shape. This earthquake has a very emergent start that is hard to pick on the long-period records. The first $35 \mathrm{~s}$ correspond to the rising ramp on the first pulse of moment release in the source time function. In this study we have not tried to resolve the details within the first $40 \mathrm{~s}$. But we find no indication of such high rupture velocities.

Kikuchi and Fukao [1987] also analyzed the $P$ waves of the Rat Islands mainshock using their multistation iterative inversion on a two-dimensional fault. They determined a source time history with a moment of $38 \times 10^{27} \mathrm{dyn} \mathrm{cm}$, very similar to our results. The spatial location of moment release determined by Kikuchi and Fukao [1987] is also very similar except that they have the largest part of the first pulse located up dip near the trench. The along-dip variations are not well resolved for this earthquake due to the long-period nature of the $P$ waveforms. 


\section{FEB. 4, 1965, RAT ISLANDS EARTHQUAKE}
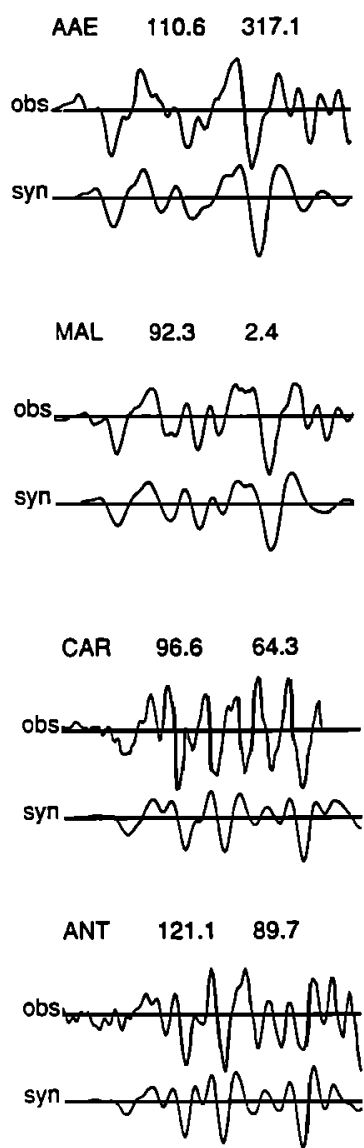
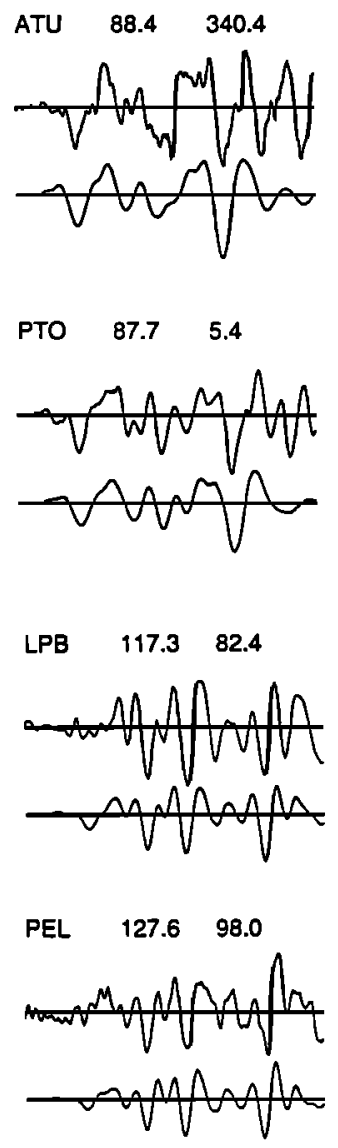
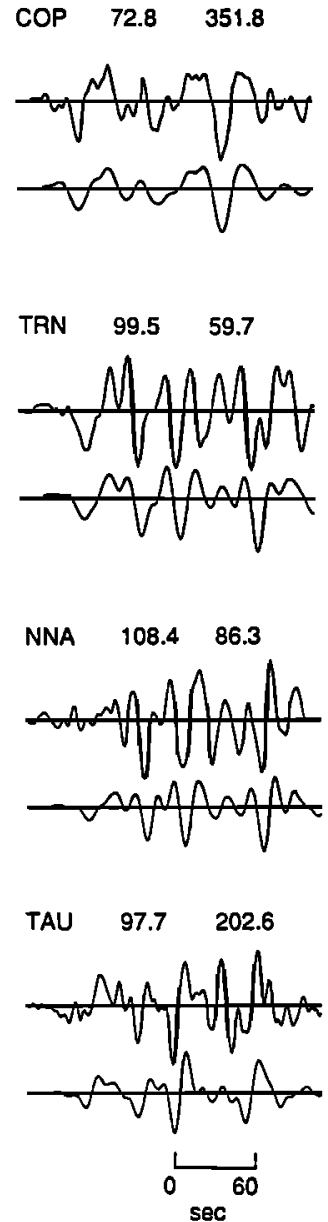

Fig. 11. The observed (top) seismograms and synthetic (bottom) seismograms for the model shown in Figure 10.

\section{Aftershocks}

There were a large number of aftershocks following the February 4, 1965, mainshock. The U.S. Coast and Geodetic survey recorded 870 aftershocks in the 45 days following the mainshock that were large enough to be routinely located [Jordan et al., 1965]. These events covered an area $\sim 650 \mathrm{~km}$ long and $\sim 200 \mathrm{~km}$ wide. Stauder [1968a] determined focal mechanisms from $P$ wave first motion and $S$ wave polarization data for the largest aftershocks. Stauder $[1968 a, b]$ found two types of focal mechanisms: (1) underthrusting mechanisms similar to the mainshock from events located arcward of the trench and (2) normal fault focal mechanisms from events occurring near the trench. These outer rise earthquakes occur trenchward of the region where we can resolve moment release (between the epicenter and $\sim 420$ $\mathrm{km})$. The largest aftershock was a normal fault event on March 30, $1965\left(M_{s}=7.5\right)$, and was located trenchward of the epicentral asperity (Figure 7). In the next section we discuss this large tensional outer rise event in more detail. Underthrusting aftershocks extend WNW of the region where we can resolve moment release from the $P$ waves (beyond $\sim 420 \mathrm{~km}$ WNW of the epicenter).

Spence [1977] relocated the aftershocks for the 1965 Rat
Islands earthquake for events having 70 or more teleseismic $P$ observations $(>M \sim 5.3)$ by the first-order arrival time difference (ATD) model. $P$ wave arrival times from the nuclear explosion Long Shot and from an event on September 27,1965 , were the reference data for the relocation. Figure 7 shows the aftershocks that occurred between the February 4, 1965, and March 30, 1965. The relocated aftershocks define an area $\sim 600 \mathrm{~km}$ along strike and $\sim 50-60 \mathrm{~km}$ wide. We have used these relocated aftershocks to define the width of faulting. There is a noticeable lack of large underthrusting type aftershocks between the epicenter and $130 \mathrm{~km}$ WNW along strike (Figure 7). This region corresponds to the location of the epicentral asperity determined from $P$ waves for the 1965 mainshock. Recent studies have examined the relationship between aftershocks and mainshock fault slip and found that for some earthquakes the regions of high mainshock slip lacked aftershocks [Mendoza and Hartzell, 1988; Choy and Dewey, 1988; Houston and Engdahl, 1989]. The lack of $M>5$ aftershocks in the epicentral asperity region for the 1965 earthquake suggests that the asperity region failed completely during the mainshock. The second asperity consists of several smaller pulses of moment release and is less coherent than the first asperity. Aftershocks 


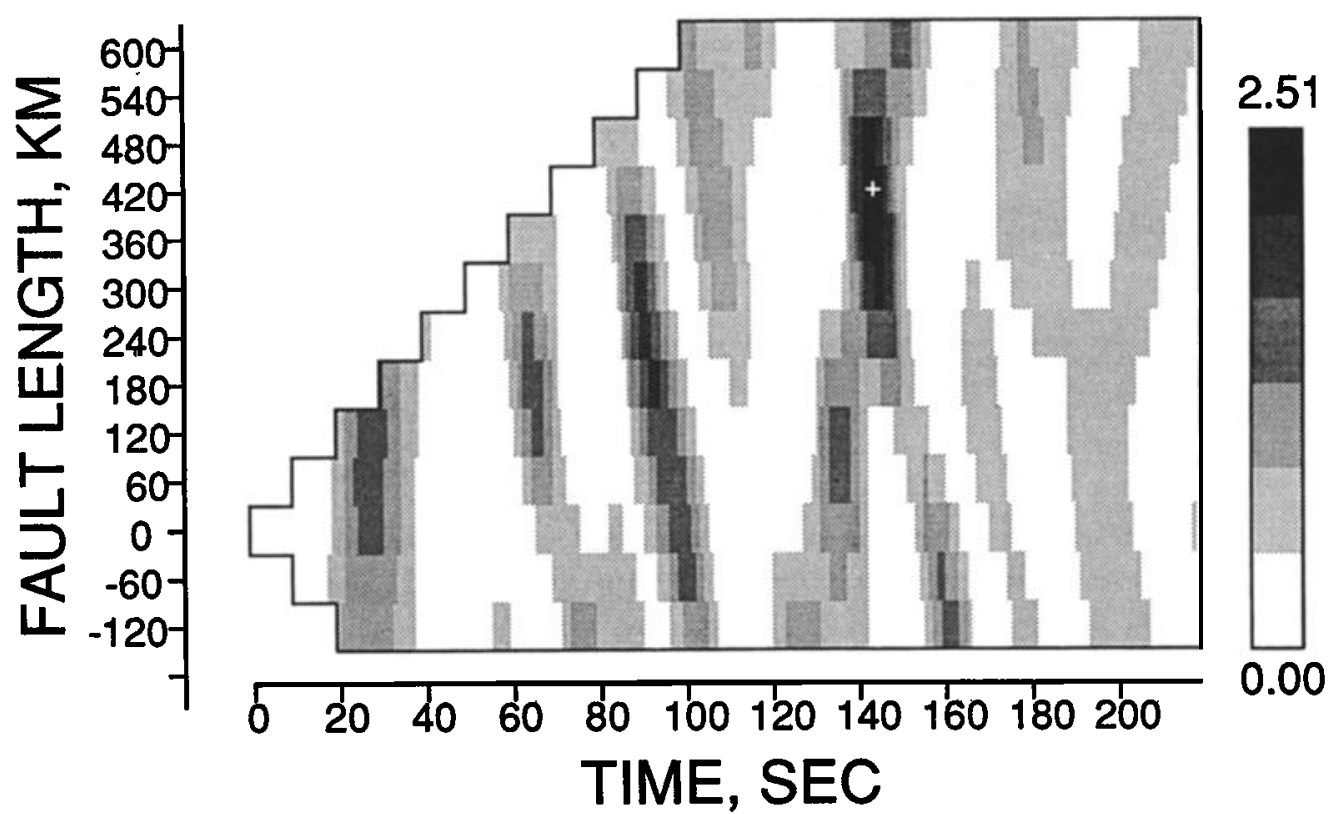

Fig. 12. Plot of the correlation coefficient function for iteration 1 from the multistation inversion. The small white cross corresponds to the location in time and space of the unit wavelet. The shading indicates the relative correlation values for each grid point. A peak of high correlation coefficients (dark shading) for the location of a wavelet indicates that it is well resolved.

overlap with the location of the second asperity (Figure 7). The third asperity region also lacks $M>5$ aftershocks (Figure 7).

\section{The March 30, 1965, Tensional Outer Rise EARTHQUAKE}

The March 30,1965, earthquake $\left(M_{s}=7.5\right)$ is among the largest extensional outer rise events to occur this century and the largest of a series of extensional outer rise events which followed the February 4, 1965, Rat Islands mainshock. These outer rise aftershocks which are located near the bathymetric trench in the oceanic crust were noted by Stauder [1968a, $b]$, who suggested that tensional stress was transmitted to the outer rise due to the incremental motion of the subducting plate (i.e., transfer of slab pull forces to the outer rise) following the February 4 mainshock. Stauder [1973] also noted a similar occurrence following the great 1960 Chile earthquake. The March 30 event occurred 2 months after the February 4 mainshock and is located just oceanward of one of the largest asperities identified in this study.

While many tensional outer rise events occur at shallow depths due to the influence of bending stresses [e.g., Chapple and Forsyth, 1979; Ward, 1983; Christensen and Ruff, 1985], it has been suggested that the larger events may rupture through the entire oceanic lithosphere [Kanamori, 1971; Abe, 1972] and represent a detachment of the downgoing slab. Abe [1972] proposed that the depth of the March 30,1965 , event extended from the surface to $\sim 60 \mathrm{~km}$ and was the result of large-scale extensional fracture of the oceanic lithosphere. Abe's conclusions were based on ISC aftershock locations. In this section we will examine the rupture process of the March 30,1965, earthquake using long-period WWSSN $P$ wave observations. We concentrated on determining the depth of this event from waveform modeling.
The focal mechanism determined by Stauder [1968a] is shown in Figure 13 along with eight azimuthally distributed source time function-seismogram pairs. The source time functions shown on the left were determined using the single-station deconvolution technique described by $R$ uff and Kanamori [1983] and assuming a point source depth of $15 \mathrm{~km}$. The waveforms and source time functions appear to be very simple at most azimuths, consisting of a simple well-defined pulse of moment release. Stations to the south and west (POO, ADE, and HNR) appear to have more complicated waveforms, although a simple moment pulse still explains the data fairly well. The later arriving energy may be due to ocean reverberations which have been amplified by a dipping ocean floor interface [see Wiens, 1989]. The total duration of the single moment pulse is $4-8 \mathrm{~s}$ with no reliable directivity.

One of the important aspects of this earthquake is to accurately determine the depth extent of faulting. We have investigated the depth using several different methods. One technique for delineating the depth is to determine source time functions for several stations using a range of depth assumptions. In Figure 14, six stations are deconvolved at depths between 2 and $70 \mathrm{~km}$, and the resulting source time functions at each depth are shown. Depth assumptions of 10 , 20 , and $30 \mathrm{~km}$ produce fairly simple impulsive source time functions. Greater depth assumptions cause periodic ringing in the source time function, which is characteristic of over estimating the depth [Christensen and Ruff, 1985]. An average seismic moment over 12 stations of $3.0 \times 10^{27} \mathrm{dyn} \mathrm{cm}$ is obtained for a depth of $15 \mathrm{~km}$. This is similar to the moment Abe [1972] determined of $3.4 \times 10^{27} \mathrm{dyn} \mathrm{cm}$ from Love and Rayleigh wave analysis.

The depth has also been investigated by using the iterative multistation inversion after Kikuchi and Kanamori [1982] and Kikuchi and Fukao [1985] described earlier. In this application we assume a point source and the focal mecha- 


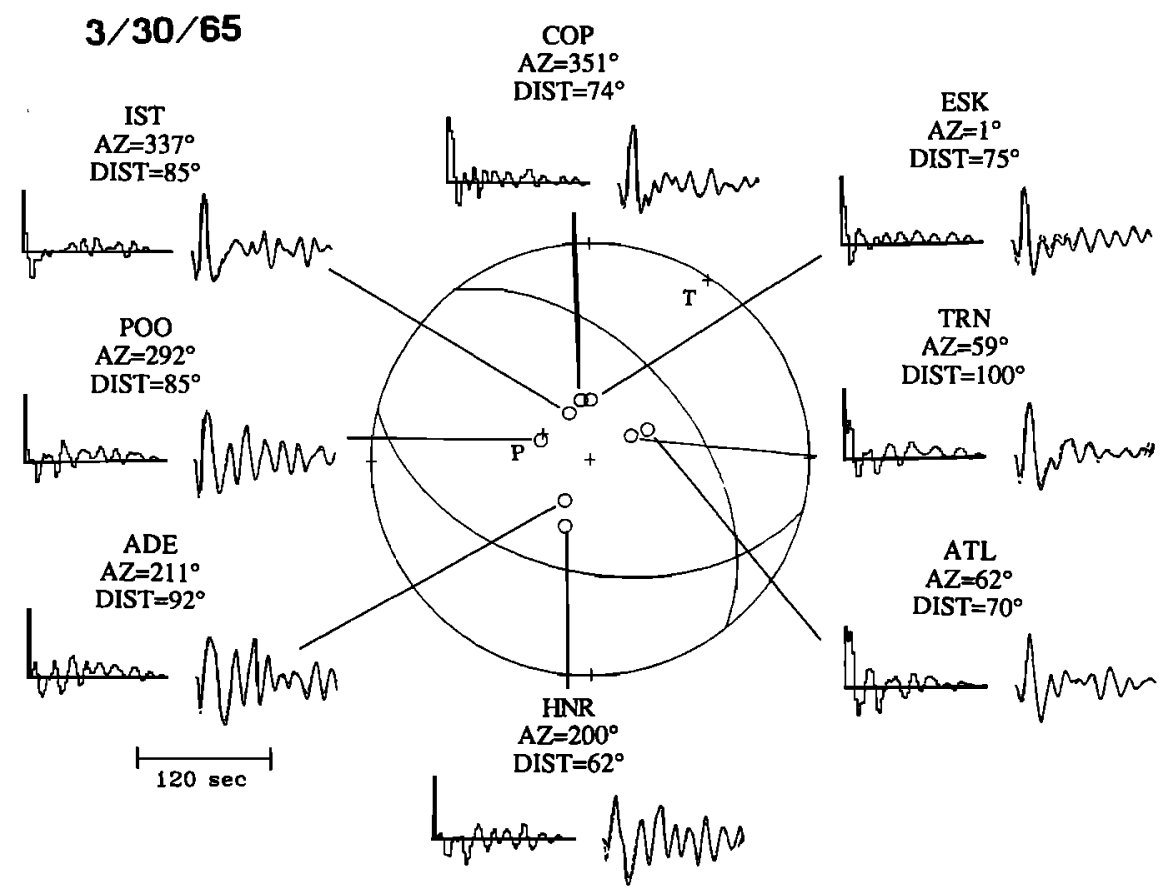

Fig. 13. Focal mechanism for the large March 30, 1965, normal fault earthquake. Representative single-station source time functions for azimuthally distributed stations are shown. The observed seismograms are the solid traces, and the synthetic seismograms for the source time function shown are the dashed traces.

nism shown in Figure 13. In Figure 15 the normalized errors between the observed and synthetic $P$ waves are plotted for assumed depths between 2 and $60 \mathrm{~km}$. The seismograms are best fit at depths between 8 and $22 \mathrm{~km}$ with a minimum error value at $18 \mathrm{~km}$ and a seismic moment of $2.1 \times 10^{27} \mathrm{dyn} \mathrm{cm}$ (Figure 15). Christensen and Ruff [1985] discuss the use of simplicity parameters applied to source time functions to help constrain depth. One such simplicity parameter, the

\section{DEPTH (km)}

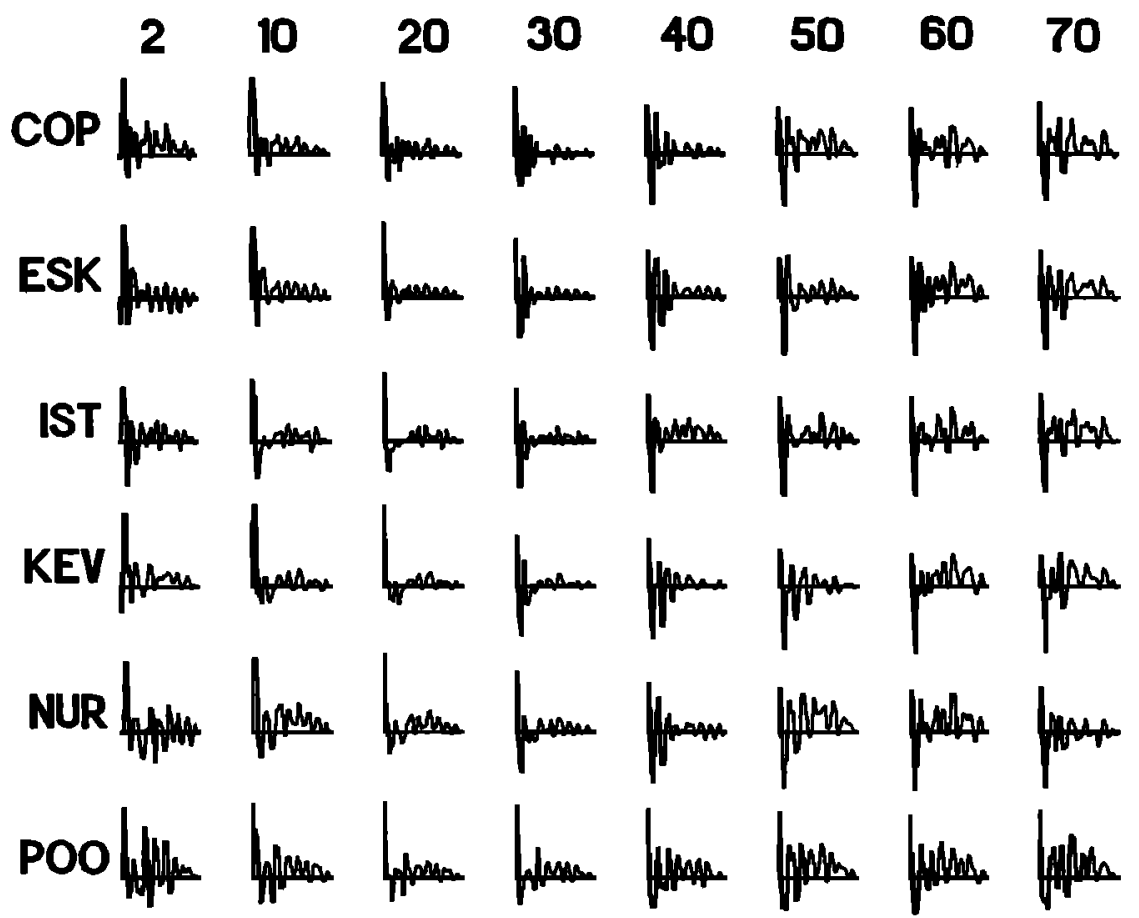

Fig. 14. Deconvolved source time functions for six stations at assumed depths for the March 30, 1965, earthquake. Source time functions for depths down to $30 \mathrm{~km}$ are simple, but for depths deeper than $30 \mathrm{~km}$ the source functions have periodic ringing, indicating an overestimation of the depth. 

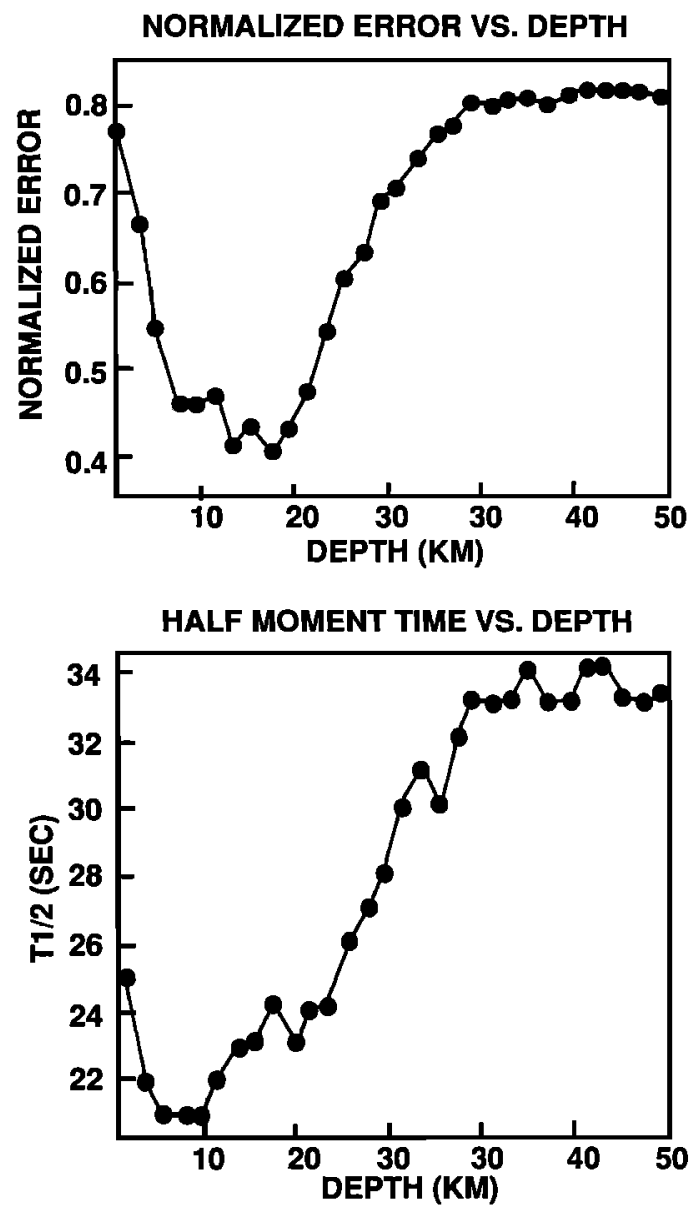

Fig. 15. The top plot is the normalized error versus depth for the multistation iterative inversion for the March 30, 1965, earthquake. The bottom plot is the half moment time versus depth for the same set of inversions as above.

absolute half moment time (HMT), which measures the concentration of moment toward the beginning of the source time functions, is plotted versus depth in Figure 15. Low values correspond to preferred depths. The HMT curve is very similar to the normalized error curve (Figure 15) and constrains the lower depth to $\sim 24 \mathrm{~km}$. Christensen and Ruff [1985] suggest that the HMT is particularly useful in constraining the lower depth extent of rupture and less sensitive to the upper depth extent.

The third depth determination method is a simultaneous omnilinear inversion technique [Ruff, 1989]. Eight azimuthally distributed $P$ wave seismograms are simultaneously inverted for the best source time function (Figure 16). This method also solves for the best amplitude scaling factors for each seismogram using the assumed focal mechanism and depth. The inversion was performed for point source depths from 2 to $60 \mathrm{~km}$ using the focal mechanism shown in Figure 13. The normalized error of the fit of the synthetic seismograms to the observed data indicates a minimum value for a depth of $24 \mathrm{~km}$ (Figure 16).

We conclude from the waveform analysis that the faulting the March 30,1965, earthquake is probably confined to the top $30-35 \mathrm{~km}$ of the crust. A review of the aftershocks used by $A b e$ [1972] to infer a depth extent down to $60 \mathrm{~km}$ shows that the events are too poorly located to substantiate the deeper extent [see Chapple and Forsyth, 1979]. Assuming a circular rupture and a rupture velocity of $3.0 \mathrm{~km} / \mathrm{s}$, the $\sim 6 \mathrm{~s}$ duration (radius of $18 \mathrm{~km}$ ) would cover an area of about 1000 $\mathrm{km}^{2}$. A rupture depth extent from 0 to $30 \mathrm{~km}$ is consistent with this calculated radius and area. These values suggest an average displacement of $6 \mathrm{~m}$ using a rigidity of $5 \times 10^{11}$ $\mathrm{dyn} / \mathrm{cm}^{2}$ and the body wave moment of $3.0 \times 10^{27} \mathrm{dyn} \mathrm{cm}$. This displacement is much larger than calculated by $A b e$ [1972] due to the smaller rupture area that we assume.

The March 30, 1965, tensional outer rise event occurred less than 2 months after the February 4, 1965, mainshock and is located oceanward of the largest asperity. The spatial and temporal association between the February 4 mainshock and the large outer rise event suggests a cause and effect relationship [see Christensen and Ruff, 1988; Dmowska and Lovison, 1988; Dmowska et al., 1988]. Stresses from the incremental motions due to the underthrusting event are transferred to the outer rise where they are combined with existing bending stress and trigger the intraplate activity. The location of this large outer rise event adjacent to the epicentral asperity is probably related to the large displacements which occurred in the region of the asperity during the mainshock.

\section{Asperity Distribution and Lateral Segmentation of the Aleutian Subduction Zone}

Many studies have identified temporal and spatial heterogeneity associated with the rupture of underthrusting subduction zone earthquakes using body waves and interpreted the spatial heterogeneity in the framework of asperities. In this study we have identified regions of high seismic moment release along strike and interpreted them as asperities. However, it is not clear what these high moment release
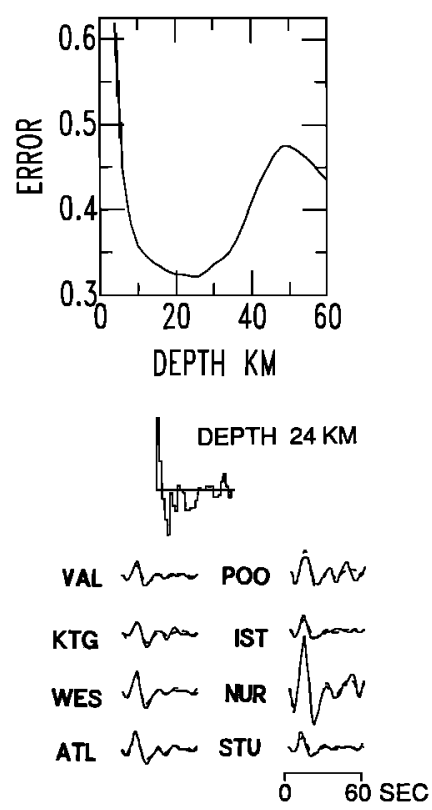

Fig. 16. The top plot is the normalized error versus depth for the omni-linear inversion for the March 30, 1965, earthquake. The inversion was preformed for depths between 2 and $60 \mathrm{~km}$. The resultant source time function from the multistation omnilinear inversion for a depth of $24 \mathrm{~km}$ is shown. The observed data are the solid traces, and synthetic seismograms for the source time function shown are the dashed traces. 
regions or asperities represent physically. From the waveform modeling we cannot determine physical properties such as the strength (i.e., strong or weak) of the plate boundary. Houston and Engdahl [1989] have found that the regions of concentrated moment release for the May 7, 1986, Andreanof Islands earthquake determined from broadband $P$ waves correspond to regions of no or few aftershocks or preshocks. They suggest that regions of high moment release in the mainshock resulted from rupture of mechanically strong regions. We do not have the resolution in the asperity locations nor extremely well located aftershocks and premainshocks to make a similar comparison.

The asperity distribution we have determined is based on the $P$ waves and accounts for $\sim 1 / 4-1 / 3$ the surface wave moment. This is also true for other large multiple asperity earthquakes such as the 1963 Kurile Islands $\left(M_{w}=8.5\right)$ [Beck and Ruff, 1987]. For many smaller earthquakes there is not a discrepancy between seismic moment determined from $P$ waves and surface waves. For example, the 1979 Colombia $\left(M_{w}=8.2\right)$ and the 1969 Kurile Islands $\left(M_{w}=8.0\right)$ earthquakes have similar seismic moments determined from the $P$ waves and surface waves [Beck and Ruff, 1984; Schwartz and Ruff, 1985]. The long-period moment release for the largest earthquakes may occur over a wider area in the dip direction than the $P$ wave moment release. We cannot evaluate the depth distribution of seismic moment release or what role variations in the width of the interplate contact play in the earthquake rupture process. Although we cannot locate this long-period moment release, we can show that it cannot be constrained in the individual pulses of moment release or asperities (Figure 4). It appears that the regions between the asperities must also have slip and therefore cannot be barriers (i.e., regions that stay locked during the earthquake). With such a small part of the total moment accounted for in the $P$ waves it is possible that the asperities that we have determined are not really significant in the overall picture of the earthquake rupture as viewed in Figures 4 and 8 . We would suggest that the temporal and spatial heterogeneities of the $P$ waves are important to understanding earthquakes. In particular, they represent one scale length of fault heterogeneity which may be important in controlling earthquake size and recurrence intervals.

Theoretical models of fault heterogeneity such as $R u d n i c k i$ and Kanamori [1981] and Rundle and Kanamori [1987] are consistent with our observations. These studies suggest that the asperity size and distribution are important in determining the total slip of the earthquake. The failure of an asperity, which may occupy a small portion of the fault plane, can cause relatively large amounts of moment release because of the additional displacement induced on the adjacent slip zones [Rudnicki and Kanamori, 1981]. These studies also indicate that multiple asperity ruptures will trigger more moment release than the sum of the moment release from totally sequential, single asperity ruptures. Rundle and $\mathrm{Ka}$ namori [1987] suggest that the failure strength of a patch (or asperity) on a fault does not determine the moment release or slip but that the interaction of the patches determines the slip.

Thatcher [1990] has compared the recurrence characteristics of great circum-Pacific earthquakes with the spatial distribution of seismic moment release in order to relate earthquake slip distributions to models of earthquake recurrence. He suggests that despite the complexity in the earth- quake rupture and variations in the earthquake cycles, there are well-order aspects of earthquake occurrence and the regions of high seismic slip may be important in controlling the recurrence behavior. If these asperities persist for several earthquake cycles along a plate boundary, then they may be critical in understanding many aspects of the earthquake occurrence. However, much more work is needed to confirm the significance of these seismically determined asperities.

\section{Lateral Segmentation of the Aleutian Arc}

Efforts to identify bathymetric features (such as fracture zones and aseismic ridges) on the downgoing plate that correlate with the asperities have generally been unsuccessful. However, we find a correlation between the lateral segmentation of the overriding plate and asperities determined from the $P$ waves for the 1965 Rat Islands earthquake. Between $180^{\circ} \mathrm{W}$ and $170^{\circ} \mathrm{E}$ along the Aleutian trench the overriding plate consists of a series of transverse tectonic canyons that cut through the Aleutian Terrace and Aleutian Ridge and trend nearly at right angles to the regional slip vector of the oceanic lithosphere [Spence, 1977]. Gates and Gibson [1956] suggested on geomorphic evidence that these canyons are of tectonic origin rather than of an erosional origin. More recently, Geist et al. [1988] have defined three rigid tectonic blocks, from east to west, the Rat block, Buldir block, and Near block (Figure 17). Geist et al. [1988] suggest these blocks formed as a result of clockwise rotation due to oblique subduction. The transverse canyons in the overriding plate are formed by differential rotation and along arc translation of the blocks [Geist et al. 1988]. The blocks are internally undeformed but separated by fault controlled canyons and extensional basins (Figure 17). The largest moment release that we identified in this study corresponds to the centers of these blocks. We suggest the central undeformed parts of the blocks may have the strongest coupling with the downgoing plate and hence are the sites of the largest moment release during an underthrusting earthquake.

The first pulse of seismic moment release occurs between the epicenter and $\sim 100 \mathrm{~km} \mathrm{WNW}$ of the epicenter. This pulse of moment release is very smooth with a long duration. This region corresponds to smooth subducting seafloor and the center of the Rat tectonic block. It also corresponds to a lack of $M>5$ aftershocks [Spence, 1977]. This correlation suggests that this region was probably strongly coupled over a large area and failed completely during the mainshock rupture. The second pulse of moment release in the source time functions is variable in character and consists of several small pulses. The locations of these pulses of moment release correspond to the Buldir block. We interpret this as an indication of several smaller regions breaking in a less strongly coupled area of the fault. This region corresponds to $M>5$ aftershocks. This might suggest that the smaller Buldir block is not as strongly coupled as the Rat block. The third pulse of moment release occurs $\sim 400 \mathrm{~km} \mathrm{WNW}$ of the epicenter and within the eastern half of the Near tectonic block. As discussed previously, we cannot distinguish between a rupture velocity of 2.5 and $3.0 \mathrm{~km} / \mathrm{s}$ corresponding to distances of 380 and $450 \mathrm{~km}$, respectively, for the third pulse of moment release. Both these locations occur within the Near tectonic block. The third pulse of moment release 


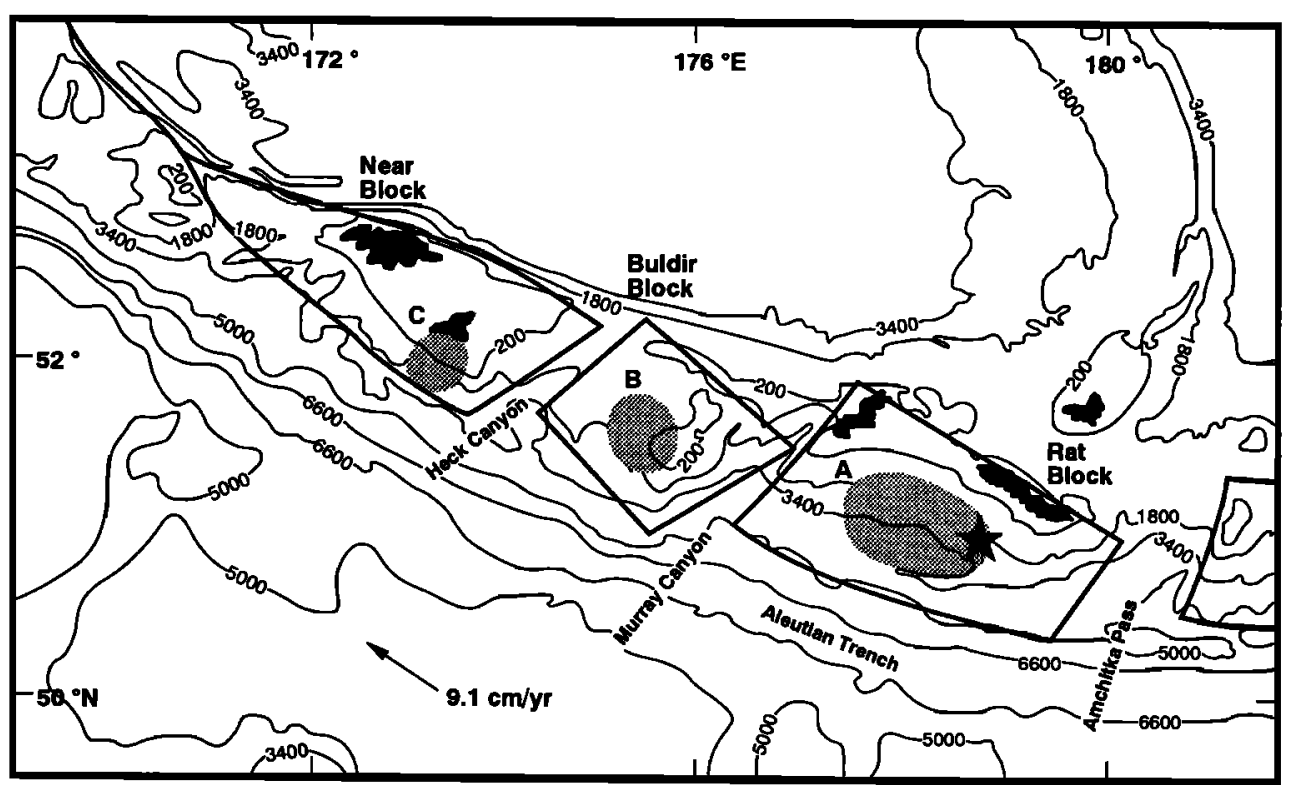

Fig. 17. Map of the western end of the Aleutian arc showing the tectonic blocks from Geist et al. [1988] and the locations of the asperities or regions of concentrated moment release identified in this study. The tectonic blocks are bounded by faults and extensional basins.

has a spatial dimension of $\sim 50 \mathrm{~km}$, about one-half that of the first pulse. The western part of the Near block is internally deformed by arc parallel strike-slip faults which may decrease the coupling between the overriding and the downgoing plates. Along the western part of the Near block the arc normal convergence is very small and approaches zero. This region had underthrusting aftershocks but no resolvable moment release from the $P$ waves of the mainshock. The $P$ wave moment release associated with the February 4, 1965 , earthquake corresponds with the lateral segmentation of the overriding plate along the Aleutian subduction zone.

\section{Slip Partitioning}

The strike of the Aleutian trench changes from $\sim 260^{\circ}$ at $180^{\circ} \mathrm{W}$ to $\sim 310^{\circ}$ at $175^{\circ} \mathrm{E}$. The average motion of the Pacific plate relative to the North American plate, calculated at $178^{\circ} \mathrm{E}$ and $51^{\circ} \mathrm{N}$, based on the Minster and Jordan [1978] model is about $8 \mathrm{~cm} / \mathrm{yr}$ at $310^{\circ}$. The subduction rate normal to the Aleutian arc at $178^{\circ} \mathrm{E}$ is $\sim 5 \mathrm{~cm} / \mathrm{yr}$ and decreases to zero westward along the arc. In some subduction zones with oblique convergence, slip partitioning into arc normal underthrusting and arc parallel strike-slip faulting has been proposed [Fitch, 1972]. Ekstrom and Engdahl [1989] show evidence for a model of slip partitioning for the central Aleutian subduction zone and suggest that it may apply to the entire Aleutian subduction zone. The relative plate motion between the North American and Pacific plates is accommodated by slip on the main thrust zone and strikeslip motion on vertical faults parallel with the volcanic arc [Ekstrom and Engdahl, 1989]. The slip vector for the Rat Islands mainshock focal mechanism determined by $W u$ and Kanamori [1973] is $330^{\circ}$ and consistent with the slip partitioning model. The slip vector determined from the plate motions is $310^{\circ}$. This $20^{\circ}$ discrepancy is similar to the discrepancy found by Ekstrom and Engdahl [1989] based on a large number of recent earthquakes. Although the slip vector is not well resolved, it is important in determining the convergence rate used for estimating the accumulated tectonic displacement across the western Aleutian arc.

\section{Previous Earthquakes Along the Western Aleutian Arc}

This same segment of the subduction zone had several large earthquakes between 1898 and 1929. From east to west they occurred on October 11, $1898\left(M_{s}=6.9\right)$; August 17, $1906\left(M_{s}=7.8\right)$; September 9, $1910\left(M_{s}=7.0\right)$; March 22, $1905\left(M_{s}=7.0\right)$; June 29, $1898\left(M_{s}=7.6\right)$; September 15, $1905\left(M_{s}=7.4\right)$; March 7, $1929\left(M_{s}=7.5\right)$; and September 2, $1907\left(M_{s}=7.4\right)$ (Figure 18) [Boyd and Lerner-Lam, 1988; Abe and Noguchi, 1983; Abe, 1981; Geller and Kanamori, 1977]. The relocations from Boyd and Lerner-Lam [1988] indicate that the events at the turn of the century cluster at the ends of the 1965 aftershock area (Figure 18). Of course, it is hard to evaluate the reliability of the locations for earthquakes at the turn of the century. The revised magnitudes by $A$ be and Noguchi [1983] are smaller than previous magnitude estimates. Abe and Noguchi [1983] evaluated the amplitudes of the surface waves recorded on undamped Miln seismographs between 1897 and 1912 and found the magnitudes to be overestimated. There are two possible interpretations for the earthquakes at the turn of the century: (1) These events are not equivalent to the 1965 mainshock and the entire plate segment did not fail. The location of the events at the edges of the 1965 zone and the revised magnitudes indicate that these events did not fail the entire 1965 zone (Figure 18). The sum of the seismic moment (estimated from the $M_{s}$ values) for the events at the turn of the century is $<10 \times 10^{27}$ dyn $\mathrm{cm}$, less than $10 \%$ of the seismic movement of the 1965 earthquake. This suggests that we have not seen a previous earthquake cycle for this region and the recurrence interval is longer than $\sim 65$ years. (2) The events at the turn of the century represent failure of the entire segment that failed in 1965 . This implies a recurrence 

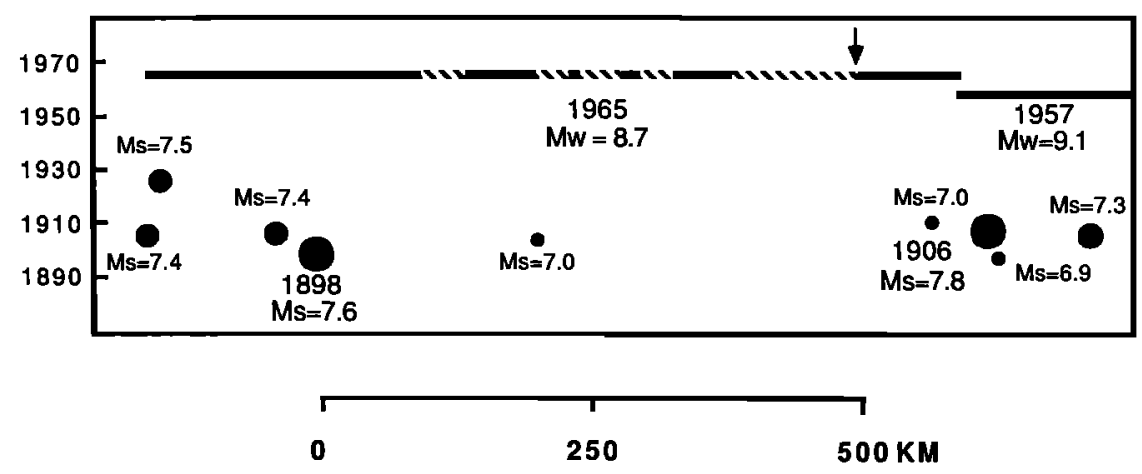

Fig. 18. Schematic space-time plot for the western Aleutian Arc. The solid bar represents the aftershock area and the hachured bars represent the dominant asperities for the February 4, 1965, earthquake. The dots represent the locations of a series of smaller earthquakes between 1898 and 1929. The events at the turn of the century tend to cluster at the edges of the 1965 Rat Island mainshock.

interval of 65 years as well as a variation in the rupture mode between successive earthquake cycles.

Sykes et al. [1981] suggested that the turn of the century earthquakes began with smaller initial events than the 1965 earthquake and thus failed to trigger rupture over the entire areas as one event. Given the lateral segmentation of the subduction zone and the corresponding segmentation of the 1965 moment release along the fault, it seems possible for the asperities to fail as individual events. The turn of the century sequence started at the western end presumably with the failure of the smaller asperity. In contrast, the 1965 mainshock started at the eastern end with the failure of the largest asperity. The failure of the larger asperity may be capable of triggering the other segments in a multiple asperity rupture. The different initiation sites could account for the variations in the rupture mode that this scenario suggests. As discussed previously, the sum of the events at the turn of the century is much less than the total seismic moment determined for the 1965 mainshock. This discrepancy in moment release between successive earthquake cycles is observed in other subduction zones (for example, the Colombia-Equador subduction zone [Kanamori and McNally, 1982]).

Nishenko and Jacob [1990] have calculated the conditional probability of a future large to great earthquake for the 1965 rupture zone assuming the turn of the century earthquakes represent an earthquake cycle. They separate the fault into two regions, the Rat Islands segment (which contains the first and second asperities of the 1965 rupture) and the Near Islands segment (which contains the third asperity of the 1965 rupture). For the Rat Islands segment they find relatively low probabilities of a future earthquake in the next 10-20 years. However, the Near Islands segment has a higher probability of $47 \%$ and $88 \%$ for the time intervals 1988-1998 and 1988-2008, respectively [Nishenko and Jacob, 1990]. This is based on previous earthquakes in 1898 and 1929 along this segment (Figure 18). More work is needed to determine the size and location of the 1929 earthquake given the high probability of recurrence in the next few decades.

If the turn of the century earthquakes represent an earthquake cycle, the accumulated tectonic displacement using a convergence rate of $8 \mathrm{~cm} / \mathrm{yr}$ is $5 \mathrm{~m}$. If the slip partition model is correct, then the component of convergence across the arc would be smaller and hence the displacement would be less. The exact value depends on the exact direction of under- thrusting and position along the arc. As discussed previously, the resolvable peak seismic displacement is $\sim 12 \mathrm{~m}$ (assuming a fault width of $60 \mathrm{~km}$ ). This value is larger than the accumulated tectonic displacement between 1900 and 1965. In fact, if we assume the asperities stay locked between subsequent earthquakes then the recurrence interval should be 160 years or more. With all the uncertainties involved in the calculated displacement, the convergence rate across the arc, and the time of the previous earthquake cycle, we cannot draw any hard conclusions. However, in other studies the accumulated tectonic displacement is larger or equal to the resolvable seismic displacement [Beck and Ruff, 1984, 1989].

We cannot distinguish positively between these two alternative interpretations for the turn of the century earthquakes. This raises the question what is an earthquake cycle. The data points toward the first possibility. The turn of the century events may not be the previous earthquake cycle. These events occurred at the edges of the 1965 rupture zone, outside the locations of the dominant asperities. If this is the case, then we do not know when the previous earthquake cycle occurred. This interpretation would change our view of the seismic potential along this segment of the subduction zone.

\section{Conclusions}

The February 4, 1965, Rat Islands earthquake $\left(M_{w}=8.7\right)$ is a multiple asperity earthquake that failed a $600-\mathrm{km}$ segment along the western Aleutian Arc. We have determined the temporal and spatial heterogeneities of the earthquake rupture from the $P$ waves for the 1965 Rat Islands earthquake. We have deconvolved WWSSN long-period teleseismic $P$ wave seismograms to obtain source time functions. Directivity associated with the three pulses of moment release in the source time functions indicate a total source duration of $160 \mathrm{~s}$, unilateral rupture in the direction of $300^{\circ}$, and an average rupture velocity of $2.5-3.0 \mathrm{~km} / \mathrm{s}$. The three pulses of moment release are located along the fault, and these regions of high moment release are interpreted as asperities. The first asperity extends from the epicenter to $100 \mathrm{~km}$ to the WNW. This is the largest asperity and corresponds to a smooth pulse of moment release in the source time function with a duration of $50 \mathrm{~s}$. The second pulse of moment release is very jagged, less coherent be- 
tween stations, and is centered $\sim 200 \mathrm{~km} \mathrm{WNW}$ of the epicenter. The third pulse of moment release occurs $\sim 420$ km WNW of the epicenter. Although the aftershock area is $\sim 600 \mathrm{~km}$ in length, we cannot resolve any moment release from the $P$ waves beyond $\sim 420 \mathrm{~km}$ WNW of the epicenter.

The locations of the regions of high moment release correspond to the segmentation of the overriding plate. The overriding plate along the western Aleutian subduction zone is laterally segmented into a series of rigid tectonic blocks separated by fault-controlled canyons and extensional basins [Geist et al., 1988]. We suggest that the central undeformed parts of the blocks have the strongest coupling with the downgoing plate and hence are the sites of the largest moment release during an underthrusting earthquake. The three asperities determined from the $\boldsymbol{P}$ waves correspond to the Rat, Buldir, and Near tectonic blocks, respectively. Hence the $P$ seismic moment release of the Rat Islands earthquake is controlled by the lateral segmentation of the overriding plate.

Acknowledgments. We thank J. E. Kaufmann for her help with the March 30, 1965, outer rise earthquake. We also thank L. Ruff and $B$. Tichelaar for providing the omnilinear inversion program. Thanks to H. Kanamori, L. Ruff, T. Lay, Paul Kasameyer, and G. Zandt for useful comments and discussion. Thanks to Goran Ekstrom and an anonymous reviewer for their comments. This work was supported by the Institute of Geophysics and Planetary Physics, Lawrence Livermore National Laboratory, and by the National Science Foundation grant EAR89-03660 to D. Christensen. Work performed under the auspices of the U.S. Department of Energy by the Lawrence Livermore Laboratory under contract W-7405-Eng48.

\section{REFERENCES}

Abe, K., Lithospheric normal faulting beneath the Aleutian trench, Phys. Earth Planet. Inter., 5, 190-198, 1972.

Abe, K., Magnitudes of large shallow earthquakes from 1904 to 1980, Phys. Earth Planet. Inter., 27, 72-92, 1981.

Abe, K., and S. Noguchi, Determination of magnitude for large shallow earthquakes 1898-1917, Phys. Earth Planet. Inter., 32, 45-59, 1983.

Beck, S., and L. Ruff, The rupture process of the great 1979 Colombia earthquake: Evidence for the asperity model, J. Geophys. Res., 89, 9281-9291, 1984.

Beck, S., and L. Ruff, Rupture process of the great 1963 Kurile Islands earthquake sequence: Asperity interaction and multiple event rupture, J. Geophys. Res., 92, 14,123-14,138, 1987.

Beck, S., and L. Ruff, Great earthquakes and subduction along the Peru Trench, Phys. Earth Planet. Inter., 57, 199-224, 1989.

Ben-Menahem, A., and M. Rosenman, Amplitude patterns of tsunami waves from submarine earthquakes, J. Geophys. Res., 77, 3097-3128, 1972.

Boyd T., and A. Lerner-Lam, Spatial distribution of turn-of-thecentury seismicity along the Alaska-Aleutian arc, Bull. Seismol. Soc. Am., 78, 636-650, 1988.

Boyd, T., and J. Nabelek, Rupture process of the Andreanof Islands earthquake of May 7, 1986, Bull. Seismol. Soc. Am., 78, 16531673, 1988.

Bullen, K. E., An Introduction to the Theory of Seismology, Cambridge University Press, New York, 1963.

Chapple, W., and D. Forsyth, Earthquakes and bending of plates at trenches, J. Geophys. Res., 84, 6729-6749, 1979.

Choy, G. L., and J. W. Dewey, Rupture process of an extended earthquake sequence: teleseismic analysis of the Chilean earthquake of March 3, 1985, J. Geophys. Res., 93, 1103-1118, 1988.

Christensen, D., and L. Ruff, Analysis of the trade-off between hypocentral depth and source time function, Bull. Seismol. Soc. Am., 75, 1637-1656, 1985.

Christensen, D., and L. Ruff, Seismic coupling and outer-rise earthquakes, J. Geophys. Res., 93, 13,421-13,444, 1988.
Dmowska, R., and L. Lovison, Intermediate term seismic precursors for some coupled subduction zones, Pure Appl. Geophys., I26, 643-664, 1988.

Dmowska, R., J. Rice, L. Lovison, and D. Josell, Stress transfer and seismic phenomena in coupled subduction zones during the earthquake cycle, J. Geophys. Res., 93, 7869-7884, 1988.

Ekstrom, G., and E. R. Engdahl, Earthquake source parameters and stress distribution in the Adak Island region of the central Aleutian Islands, Alaska, J. Geophys. Res., 94, 15,499-15,519, 1989.

Fitch, T. J., Plate convergence, Transcurrent faults, and internal deformation adjacent to southeast Asia and the western Pacific, $J$. Geophys. Res., 77, 4432-4460, 1972.

Forsyth, D. W., Determinations of focal depths of earthquakes associated with the bending of oceanic plates at trenches, Phys. Earth Planet. Inter., 28, 141-160, 1982.

Furumoto, M., Initial phase analysis of $R$ waves from great earthquakes, J. Geophys. Res., 84, 6867-6874, 1979.

Gates, O., and W. Gibson, Interpretation of the configuration of the Aleutian Ridge, Geol. Soc. Am. Bull., 67, 127-146, 1956.

Geist, E. L., J. R. Childs, and D. W. Scholl, The origin of Summit basins of the Aleutian Ridge: Implications for block rotation of an arc massif, Tectonics, 7, 327-342, 1988.

Geller, R., and H. Kanamori, Magnitude of great shallow earthquakes from 1904 to 1952, Bull. Seismol. Soc. Am., 67, 587-598, 1977.

Hayes, D. E., and J. R. Heirtzler, Magnetic anomalies and their relation to the Aleutian Island Arc, J. Geophys. Res., 73, 46374646, 1968.

Houston, H., and E. R. Engdahl, A comparison of the spatiotemporal distribution of moment release for the 1986 Andreanof Islands earthquake with relocated seismicity, Geophys. Res. Lett., 16, 1421-1424, 1989.

Jordan, J. N., J. F. Lander, and R. A. Black, Aftershocks of the 4 February 1965 Rat Island earthquake, Science, 148, 1323-1325, 1965.

Kanamori, H., Seismological evidence for a lithospheric normal faulting-The Sanriku earthquake of 1933, Phys. Earth Planet. Inter., 4, 289-300, 1971.

Kanamori, H., The nature of seismicity patterns before large earthquakes, in Earthquake Prediction, An International Review, Maurice Ewing Ser., vol. 4, edited by D. W. Simpson and P. G. Richards, pp. 1-19, AGU, Washington, D. C., 1981.

Kanamori, H., and K. C. McNally, Variable rupture mode of the subduction zone along the Ecuador-Colombia Coast, Bull. Seismol. Soc. Am., 72, 1241-1253, 1982.

Kikuchi, M., and Y. Fukao, Iterative deconvolution of complex body waves from great earthquakes-Tokachi-Oki earthquake of 1968, Physics Earth. Planet. Inter., 37, 235-248, 1985.

Kikuchi, M., and Y. Fukao, Inversion of long-period $P$ waves from great earthquakes along subduction zones, Tectonophysics, 144, 231-247, 1987.

Kikuchi, M., and H. Kanamori, Inversion of complex body waves, Bull. Seismol. Soc, Am., 72, 491-506, 1982.

Lay, T., and H. Kanamori, An asperity model of large earthquake sequences, in Earthquake Prediction, An International Review, Maurice Ewing Ser., vol. 4, edited by D. W. Simpson and P. G. Richards, pp. 579-592, AGU, Washington, D. C., 1981.

Lay, T., H. Kanamori, and L. Ruff, The asperity model and the nature of large subduction zone earthquakes, Earthquake Predict. Res., I, 3-71, 1982.

Mendoza, C., and S. H. Hartzell, Aftershock patterns and mainshock faulting, Bull. Seismol. Soc. Am., 78, 1438-1449, 1988.

Minster, J., and T. Jordan, Present-day plate motions, J. Geophys. Res., 83, 5331-5354, 1978.

Mori, J., Short- and long-period subevents of the 4 February 1965 Rat Islands earthquake, Bull. Seismol. Soc. Am., 74, 1331-1347, 1984.

Nishenko, S. P., and K. H. Jacob, Seismic potential of the Queen Charlotte-Alaska-Aleutian seismic zone, J. Geophys. Res., 95, 2511-2532, 1990.

Rudnicki, J. W., and H. Kanamori, Effects of fault interaction on moment, stress drop, and strain energy, J. Geophys. Res., 86, 1785-1793, 1981.

Ruff, L., Tomographic imaging of seismic sources, in Seismic 
Tomography, edited by G. Nolet, pp. 339-366, D. Riedel, Hingham, Mass., 1987.

Ruff, L. J., Multi-trace deconvolution with unknown trace scale factors: Omnilinear inversion of $P$ and $S$ waves for source time functions, Geophys. Res. Lett., 16, 1043-1046, 1989.

Ruff, L., and H. Kanamori, Seismicity and the subduction process, Phys. Earth Planet. Inter., 23, 240-252, 1980.

Ruff, L., and H. Kanamori, The rupture process and asperity distribution of three great earthquakes from long-period diffracted $P$ waves, Phys. Earth Planet. Inter., 31, 202-230, 1983.

Rundle, J. B., and H. Kanamori, Application of an inhomogeneous stress (patch) model to complex subduction zone earthquakes: A discrete interaction matrix approach, J. Geophys. Res., 92, 26062626, 1987.

Schwartz, S., and L. Ruff, Asperity distribution and earthquake occurrence in the southern Kurile Arc, Phys. Earth Planet. Inter., 49, 54-77, 1987.

Spence, W., The Aleutian Arc: Tectonic blocks, episodic subduction, strain diffusion and magma generation, J. Geophys. Res., 82, 213-230, 1977.

Stauder, W., Mechanism of the Rat Island earthquake sequence of February 4, 1965, with relation to island arcs and sea floor spreading, J. Geophys. Res., 73, 3847-3858, $1968 a$.

Stauder, W., Tensional character of earthquake foci beneath the Aleutian trench with relation to sea floor spreading, J. Geophys. Res., 73, 7693-7701, $1968 b$.

Stauder, W., Mechanism and spatial distribution of Chilean earthquakes with relation to subduction of the oceanic plate, $J$. Geophys. Res., 78, 5033-5061, 1973.

Sykes, L., J. B. Kisslinger, L. S. House, J. N. Davies, and K. H.
Jacob, Rupture zones and repeat times of great earthquakes along the Alaska-Aleutian Arc, in Earthquake Prediction, An International Review, Maurice Ewing Ser., vol. 4, edited by D. W. Simpson and P. G. Richards, pp. 73-80, AGU, Washington, D. C., 1981 .

Thatcher, W., Order and diversity in the modes of circum-Pacific earthquake recurrence, J. Geophys. Res., 95, 2609-2623, 1990.

Ward, S. N., Body wave inversion: Moment tensors and depths of oceanic intraplate bending earthquakes, J. Geophys. Res., 88, 9315-9330, 1983.

Weins, D. A., Bathymetric effects on body wave forms from shallow subduction zone earthquakes and application to seismic processes in the Kurile trench, J. Geophys. Res., 94, 2955-2972, 1989.

Wu, F. T., and H. Kanamori, Source mechanism of February 4, 1965, Rat Island earthquake, J. Geophys. Res., 78, 6082-6092, 1973.

Young, C. J., T. Lay, and C. S. Lynnes, The February 4, 1976 Guatemalan earthquake: A bilateral rupture, Bull. Seismol. Soc. Am., 79, 670-689, 1989.

S. L. Beck, Department of Geosciences, Gould Simpson Building, University of Arizona, Tucson, AZ 85721.

D. H. Christensen, Geophysical Institute University of Alaska, Fairbanks, Fairbanks AK 99775.

(Received November 13, 1989; revised July 12, 1990;

accepted August 17, 1990.) 